\title{
Next-generation surgical meshes for drug delivery and tissue engineering applications: materials, design and emerging manufacturing technologies
}

\author{
Francesca Corduas $^{1,2}$. Dimitrios A. Lamprou ${ }^{2}$. Elena Mancuso ${ }^{1}$ (D)
}

Received: 29 July 2020 / Accepted: 24 October 2020 / Published online: 5 January 2021

(C) The Author(s) 2021

\begin{abstract}
Surgical meshes have been employed in the management of a variety of pathological conditions including hernia, pelvic floor dysfunctions, periodontal guided bone regeneration, wound healing and more recently for breast plastic surgery after mastectomy. These common pathologies affect a wide portion of the worldwide population; therefore, an effective and enhanced treatment is crucial to ameliorate patients' living conditions both from medical and aesthetic points of view. At present, non-absorbable synthetic polymers are the most widely used class of biomaterials for the manufacturing of mesh implants for hernia, pelvic floor dysfunctions and guided bone regeneration, with polypropylene and poly tetrafluoroethylene being the most common. Biological prostheses, such as surgical grafts, have been employed mainly for breast plastic surgery and wound healing applications. Despite the advantages of mesh implants to the treatment of these conditions, there are still many drawbacks, mainly related to the arising of a huge number of post-operative complications, among which infections are the most common. Developing a mesh that could appropriately integrate with the native tissue, promote its healing and constructive remodelling, is the key aim of ongoing research in the area of surgical mesh implants. To this end, the adoption of new biomaterials including absorbable and natural polymers, the use of drugs and advanced manufacturing technologies, such as 3D printing and electrospinning, are under investigation to address the previously mentioned challenges and improve the outcomes of future clinical practice. The aim of this work is to review the key advantages and disadvantages related to the use of surgical meshes, the main issues characterizing each clinical procedure and the future directions in terms of both novel manufacturing technologies and latest regulatory considerations.
\end{abstract}

Elena Mancuso

e.mancuso@ulster.ac.uk

$1 \quad$ Nanotechnology and Integrated Bio-Engineering Centre (NIBEC), Ulster University, Jordanstown Campus, Newtownabbey BT37 0QB, UK

2 School of Pharmacy, Queen's University Belfast, Belfast BT9 7BL, UK 


\section{Graphic abstract}

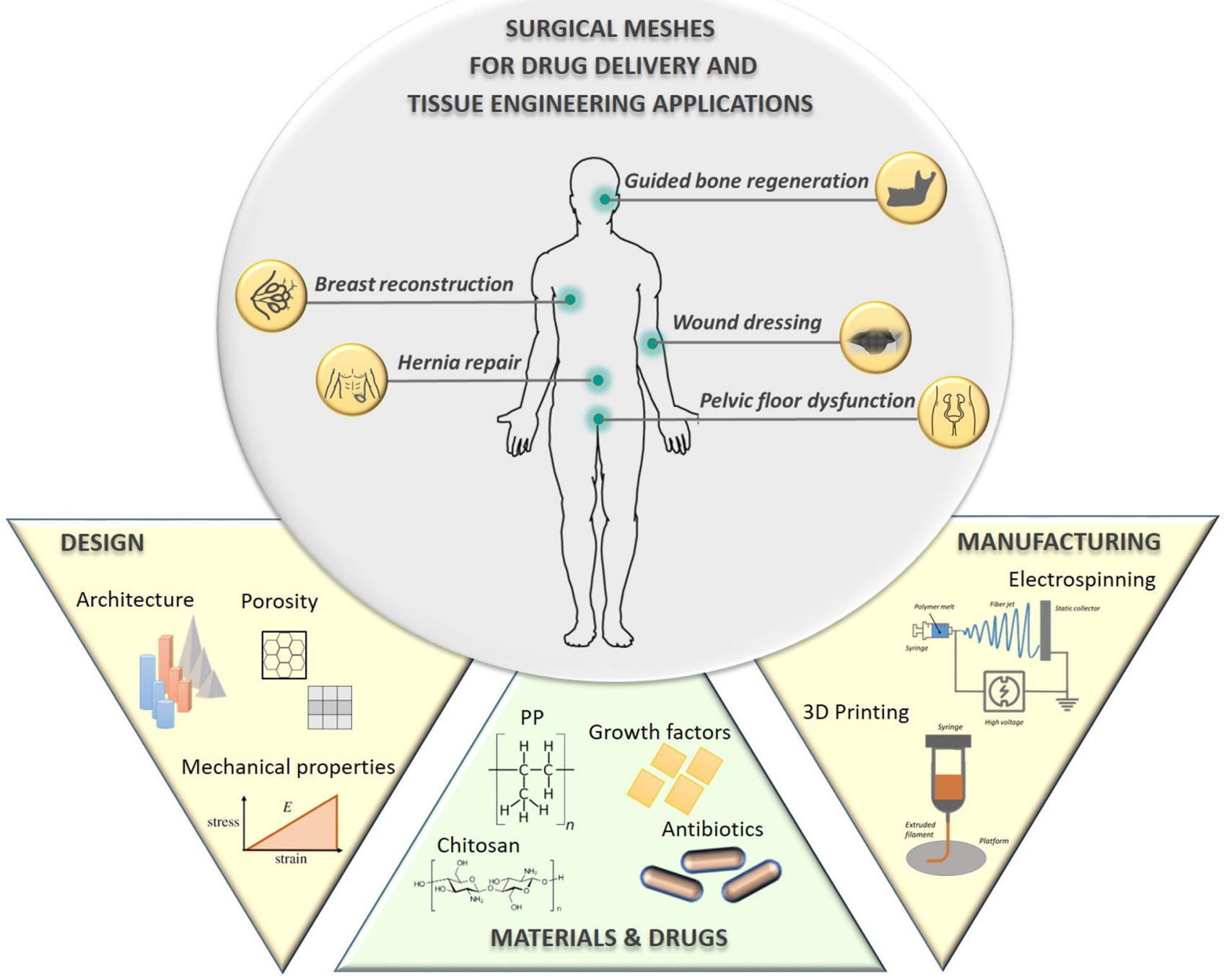

Keywords 3D printing $\cdot$ Electrospinning $\cdot$ Manufacturing technologies $\cdot$ Biomaterials $\cdot$ Drug delivery $\cdot$ Surgical mesh implants

\section{General introduction}

Surgical mesh implants are generally defined as flexible and thin flat sheets [1] that are commonly used to provide additional support to a weakened tissue [2]. The first meshes used in clinical practice date back to 1950s, when they were explored for the treatment of hernia conditions [3]. Meshes for hernia repair applications provided a tension-free reinforcement for the injured tissue [4] that resulted in better outcomes both in terms of tissue integration and consequent repair [3]. Having noticed the improvements reported in the treatment of hernia, in 1970s meshes were introduced for the management of pelvic floor dysfunctions (PFDs), including pelvic organ prolapse (POP) and stress urinary incontinence
(SUI), with the first urogynaecological mesh approved by the US Food and Drug Administration (FDA) only 20 years ago [5].

The ability to provide mechanical support to weak tissues was subsequently exploited in other clinical fields. For instance, in 2001 meshes were introduced to expand the size of the reconstructive pocket in breast reconstructive surgery after mastectomy [6]. Surgical meshes have also been used to create an isolated environment for tissue regeneration. Particularly, guided bone regeneration (GBR) membranes have been extensively used as an efficient method for the reconstruction of both structure and function of alveolar bone defects before dental implant placement. Through this approach, the membrane is used to cover the defect site and 
direct the growth of new bone while preventing the infiltration of connective tissue into the defected area [7]. GBR meshes need different features with respect to those employed in hernia repair, mainly osteoinduction, which is the ability to recruit mesenchymal stem cells (MSCs) and influence their differentiation into osteoblasts, and osteoconduction, which is the ability of the mesh to guide bone tissue formation [8]. Finally, the use of meshes in the form of dressings for wound healing applications intended to create a "safe space" for the wound bed, acting as a barrier against the external environment, preventing bacterial contamination, absorbing exudates and keeping it clean [9].

Up to now, meshes have been produced mainly using nonabsorbable materials, especially for hernia and PFDs. They have been developed as an alternative to biological prostheses, aiming to overcome the limitations related to their use, such as the possibility to develop infections, unpredictable mechanical properties and the high risk associated with tissue harvesting procedures [3, 5]. However, their employment is also linked to a vast number of post-operative complications, with infection the most common one in hernia [3], PFDs [5], GBR [7] and breast reconstruction (BR) [10]. Other complications include the arising of chronic immune reaction and subsequent fibrotic process [11] and device mechanical failure. Especially concerning meshes employed in PFDs, several restrictions have been imposed on their use by FDA and by the National Health Service (NHS) in UK, due to the substantial amount of side effects related to their use. These issues, in turn led to an important decrease in the number of mesh-based surgical procedures (from 13,990 in 2008 to 7245 in 2016 for SUI and from 3073 in 2008 to 2680 in 2016 for POP) [12] and, in some countries, to their complete ban $[13,14]$.

Therefore, many efforts have been made in the last years to improve meshes' performances, particularly in terms of antibacterial behaviour, material selection and manufacturing process. Aiming to mitigate the immune reaction and counteract infections, a wide range of antibacterial agents and drugs have also been investigated (e.g. antibiotics, metallic nanoparticles, natural antimicrobials, bio-molecules) [15, 16], as well as absorbable and naturally derived materials (e.g. collagen, chitosan, alginate) [7, 17]. Additionally, the lack of patient-specific solutions has led to the employment of new technologies [18] aiming to develop personalized devices and to improve the integration with the native tissue. The feasibility of additive manufacturing (AM) and electrospinning has been extensively studied to deal with the personalized manufacturing strategies for such applications. Their exploitation could be promising to design patientspecific devices with reproducible geometrical features and increased biomimetic activity $[19,20]$.

Some of the mentioned clinical conditions, although not life threatening, are very common into the worldwide popu- lation and can have a negative impact on patients' social life and psychology. Furthermore, the amount of money spent for the treatment of these pathologies is high. Specifically, in Europe the total expenditure for the management of PFDs is 10 billion euros [7, 19], while around 6 million dollars and 15 million dollars are estimated to be invested in hernia and wound care devices respectively, by 2027 [21, 22]. Up to now, for each clinical condition no ideal surgical mesh device exists, and despite the big number of commercially available products, they still suffer from several limitations [18]. Therefore, the aim of this review is to provide an overview on the use of novel materials, drugs and antimicrobial agents in combination with emergent technologies for the manufacturing of drug-eluting meshes. The need for mesh designs more compliant to patients' anatomy, in order to better integrate within the surrounding tissue and thus reduce the number of post-operative complications are then reviewed and discussed. Ultimately, insights about current regulatory considerations and the potential further research holds, in order to advance current clinical practice, are provided.

\section{Clinical applications}

According to the specific field of application as well as clinical need, meshes can be adopted by surgeons via different types of surgical procedures and with the final aim to provide mechanical support, healing and tissue repair.

\section{Hernia}

From a clinical perspective, hernias are caused by the protrusion of internal organs out of the abdomen, mainly due to the presence of a weak spot or a hole into the surrounding connective and muscular tissue [2, 23] and can be classified into two different groups according to the protrusion location. Groin hernias are located in the bottom half of the body [24]. They mainly affect the male population with an incidence between the 27 and 43\% [25]. Ventral hernias are located in the superior half of the body [24], and many times, they are referred to us as incisional hernias, since occur as consequence of weaknesses developed after laparoscopic abdominal surgery [26]. The current treatment of hernia includes mesh-based surgery, with 91,673 operations performed in 2018 in UK [12]. The reference standard is the Lichtenstein open "tension-free" procedure [25]. Traditional surgical procedures consisted of the superimposition of tissues which were not normally overlapped, thus introducing undesirable tension [27]. Lichtenstein approach consists in the fixation of the mesh (via tissue glues, tacks, staples or stitches) onto the aponeurotic tissue after having made an incision above the defect, thus considerably decreasing the level of tension to which the tissue will be subjected [24, 27]. Unfortunately, Lichtenstein 
A
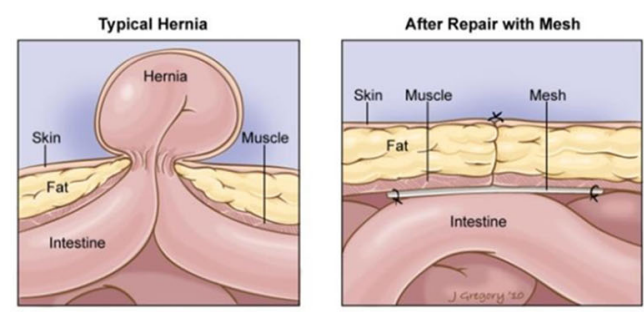

C

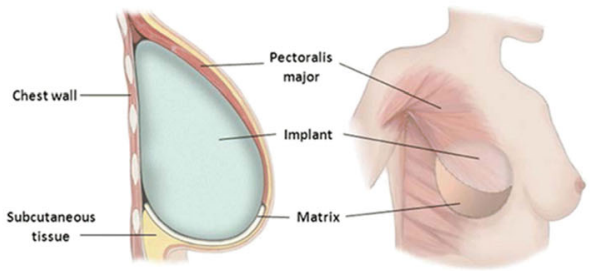

B
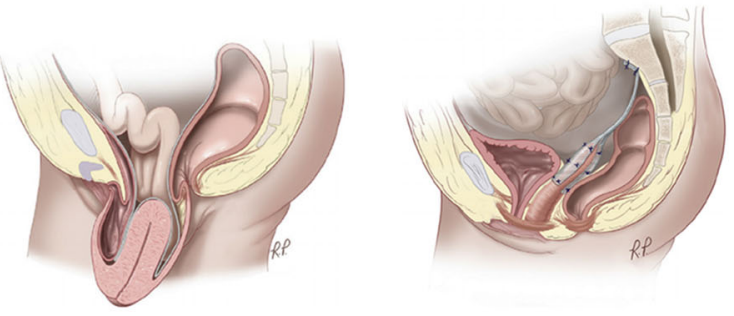

D

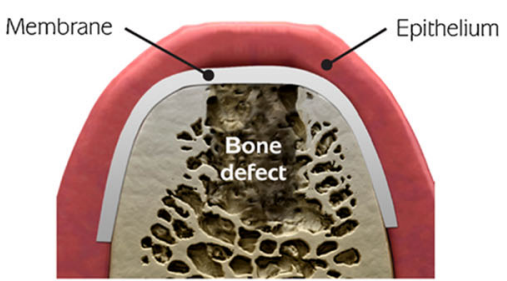

E

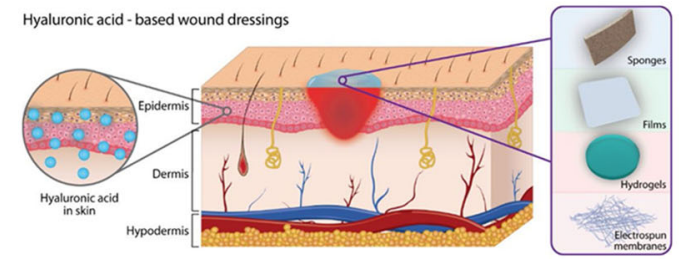

Fig. 1 Schematization of the use of surgical meshes. a Left representation of hernia pathology, in which a small part of the intestine protrudes from the abdominal wall; a Right hernia treatment via placement of surgical mesh. Reprinted from [23], Copyright under Creative Commons Attribution Licence CC BY 3.0. b Left Apical compartment prolapse in PFDs; b Right Sacrocolpopexy. Reprinted from [29], Copyright 2015 Elsevier Inc. c Implant and mesh positioning in BR. Reprinted from [10],

approach has been associated in $63 \%$ of the cases with the arising of chronic pain, thus affecting patients' quality of life. So recently, the laparoscopic approach [transabdominal preperitoneal (TAPP) and totally extraperitoneal (TEP)] has gained a lot of attention because it makes the surgery safer and less invasive [25] (Fig. 1a).

\section{Pelvic floor dysfunctions}

POP is due to the inability of the pelvic floor to support organs of the pelvic cavity (e.g. urethra, bladder, vagina, uterus, cervix and rectum), thus causing their descendance from their original position [28]. The weakening of the pelvic floor, which is more common in the elder population (postmenopause women) [29, 30], is also the main cause for the arising of SUI, which is characterized by the uncontrolled spillage of urine due to the failure of the sphincter muscle [31]. It has been reported that PFDs develop in the $17 \%$ of the female population. Specifically, up to $73 \%$ of women suffer from POP and more than the $40 \%$ is affected by SUI [30].

According to the specific prolapsed organ, PFDs can be grouped in four types [32]:
Copyright 2016 Logan Ellis et al. under Creative Commons Licence CC BY 4.0. d GBR surgical mesh placement between the epithelium and the underlying bone defect. Reprinted from [16], Copyright 2012 Academy of Dental Materials. e Examples of hyaluronic acid-based wound dressings for wound healing applications. Reprinted from [49], Copyright 2020 Elsevier Ltd

- Anterior prolapse, characterized by the bulging of the bladder into the front wall of the vagina.

- Uterine prolapse, in which the womb protrudes out of the vagina.

- Vaginal prolapse, caused by the sagging of the upper part of the vagina.

- Posterior prolapse, due to the protrusion of the bowel into the back wall of the vagina.

There are several ways in which POP and SUI could be managed, which include non-surgical and surgical treatments [28]. Non-surgical treatments include life-style changes, such as weight loss, pelvic floor exercises, hormone treatments and the application of pessaries [28, 32]. Among the most common surgical procedures, anterior colporrhaphy or sacrospinous ligament fixation can be carried out without the use of meshes [33]. Instead, sling surgery [34] (especially used in the treatment of SUI [31]) and sacrocolpopexy (both via open surgery and with a laparoscopic approach) require the use of a prosthesis in order to restore the normal positions of the organs. Sling surgery is performed by inserting a mid-ureteral sling/tape to provide additional support to the urethra. Sacrocolopexy, instead, consist in the placement of a mesh from the sacrum to the vagina/uterus [35] (Fig. 1b). 
Currently, NHS advise to use vaginal meshes as last resort due to significant amount of post-operative complications, which include pain, nerves damages and sexual problems among other issues [34]. Additionally, in some other countries, such as New Zealand and Australia, vaginal meshes have been completely banned and are no longer supplied $[13,14]$. The regulatory considerations on the use of vaginal surgical meshes will be discussed in "Regulatory considerations" section.

\section{Breast surgery}

The mechanical support exerted by meshes has also been used by surgeons during BR after mastectomy. Mastectomy consists in the partial or complete removal of the breast aiming to eliminate cancer, especially in those cases in which tumour cells have spread throughout all that area. Due to the physical and psychological burden, very often surgeons suggest the possibility to have a reconstruction [36]. In the UK, reconstructive surgery is performed in the $60 \%$ of the cases [37]. It consists in putting a saline or silicone implant under the skin or the muscles of the chest (subcutaneous and submuscular approach respectively) [38, 39]. Lately, prepectoral approach, through which the mesh is sutured to the inferior margin of the major pectoralis muscle, has become really promising since it allows to create a larger reconstructive fold, thus making the final implant more stable and comfortable $[10,38]$ (Fig. 1c).

\section{Periodontal surgery}

Mesh implants have also been exploited to provide a growth support during periodontal surgery, helping in the restoration of periodontium or of the alveolar bone prior to dental implant insertion. Periodontium is a complex tissue whose primary aim is to anchor the tooth to the mandible. It interfaces on one side with the root cementum and on the other side with the alveolar bone, which is the main support for teeth and gingiva [40]. Periodontitis is a very common disease (half of the US population is affected [41]) characterized by the gradual destruction of periodontium, often resulting in tooth and alveolar bone loss, as well as gingiva recession [40]. There are several ways in which this condition can be managed, among which guided tissue regeneration (GTR) and GBR are of interest for this review. The main difference between the two approaches relates to the fact that GTR is primarily used to restore the function of periodontium while GBR is used to help the growth of the alveolar bone [16]. However, in both the cases, the surgical procedure consists in the sub-gingival placement of a membrane in the defect site aiming to provide an isolate environment for tissue growth and regeneration [16, 42] (Fig. 1d).

\section{Wound dressings}

Meshes in the form of dressings have been widely employed also in the treatment of wounds. Wound management has become crucial due to the high incidence of deaths every year caused by burns (almost 180,000 deaths per year) [43] and the frequent development of chronic leg ulcerations [44].

Chronic wounds may develop when the healing process fails to progress through its normal stages, due to the presence of underlying pathologies, such as venous or arterial problems $[44,45]$ and thus causing an impairment in tissue regeneration and formation [46, 47]. TIME (tissue, infection, moisture, edge) and TWA (triangle of wound assessment) approaches, which are based on the wound examinations, are very common practises in order to choose the clinical plan [45]. Current management approaches rely on wound debridement, infection prevention strategies, biological therapies [45] and on the use of passive dressings such as gauzes [48]. However, these strategies are often non-specific and unable to address all the problems related to impaired wound healing, such as moisture and pressure control and exudates absorption. Also, the use of passive dressings frequently result in poor outcomes, mainly related to the arising of secondary trauma or their inability to provide an efficient barrier against the external environment [45, 48]. All these issues have led to the development of new bioactive dressings, which could play an active role in the healing process, providing a moist environment in the wound site, allowing gas exchange, preventing infections and protecting the wound from the external space [9, 49] (Fig. 1e).

Currently, a significant number of surgical meshes are available on the market. They are made of different materials and characterized by different levels of inflammatory response, tissue infiltration, biodegradation rate and stability. In Table 1 are reported some examples of meshes currently employed in clinical practice for the treatment of hernia, PFDs, BR, wound healing, GBR procedures, including details about their material composition and key properties.

\section{Mesh-related complications}

The use of surgical meshes could potentially lead to significant improvements in terms of clinical outcomes, considering their ability to support cell growth and collagen production [3]. Their use is still accompanied by several drawbacks, which are listed in Table 2 according to the different clinical application. The adverse events have been found to mainly relate to the material used, mesh design and manufacturing method.

One of the major issues is immune reaction. Even if materials used in biomedical applications are biocompatible, their 


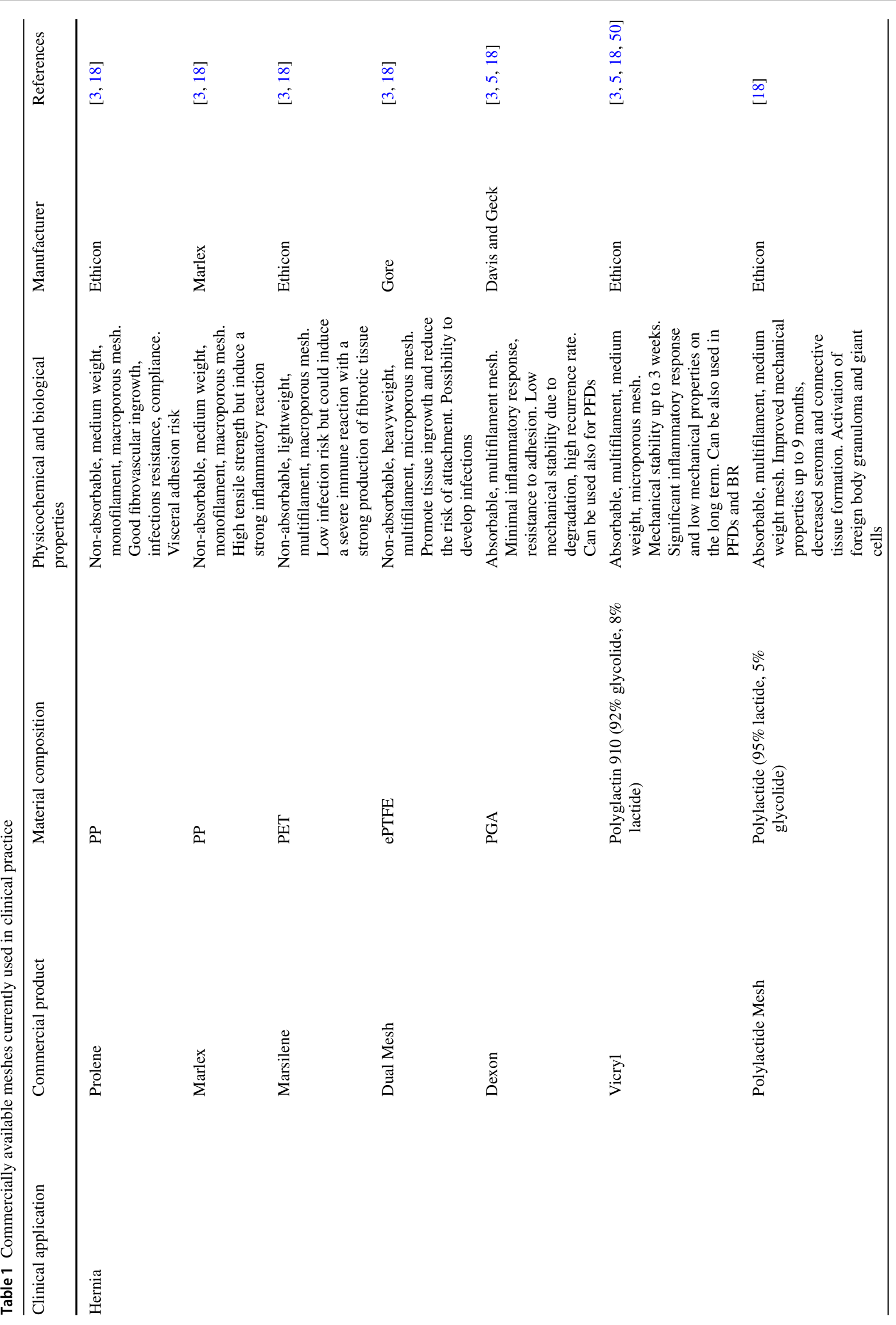




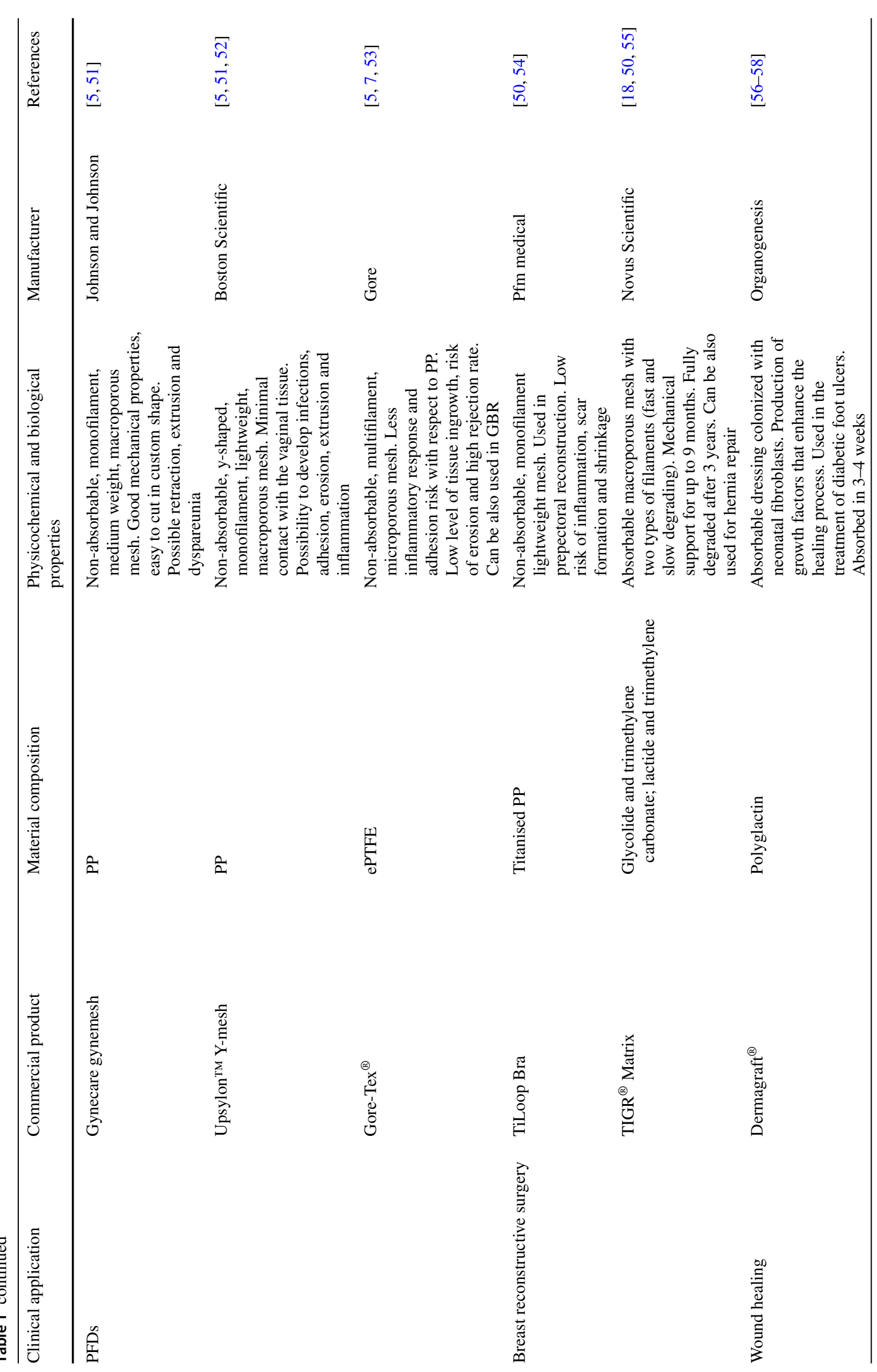




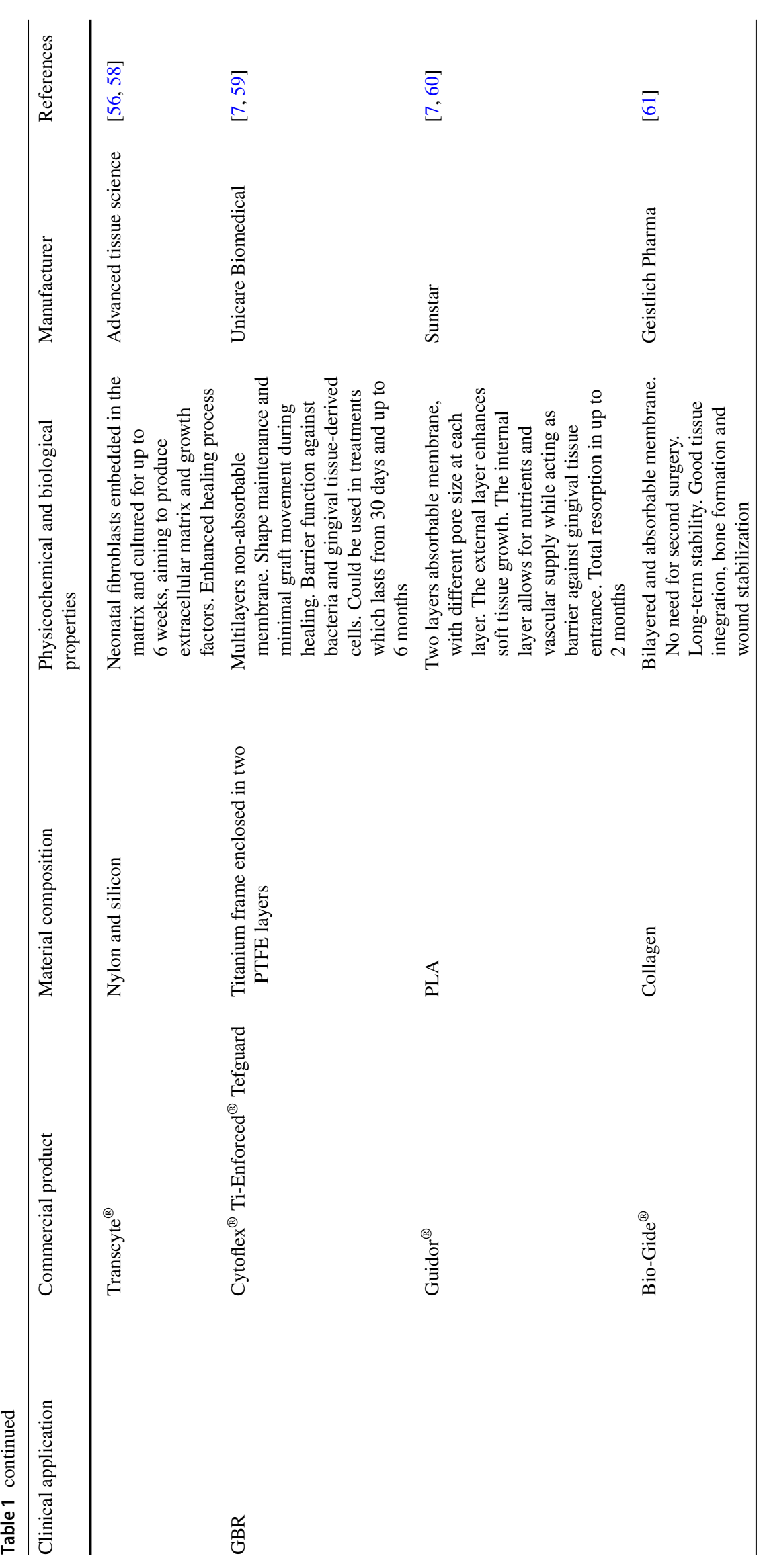


Table 2 Major complications commonly associated with the use of surgical meshes in clinical practice

\begin{tabular}{|c|c|c|c|}
\hline $\begin{array}{l}\text { Clinical } \\
\text { application }\end{array}$ & Complication(s) & Incidence (\%) & References \\
\hline \multirow[t]{5}{*}{ Hernia } & Seroma & 3.3 & \multirow[t]{5}{*}{ [71] } \\
\hline & Hematoma & 7.9 & \\
\hline & Infections & 1.5 & \\
\hline & Recurrence & $42-57$ & \\
\hline & Pain & $10-12$ & \\
\hline \multirow[t]{8}{*}{ POP } & Erosion & 35.1 & \multirow[t]{8}{*}[72]{} \\
\hline & Pain & 31.4 & \\
\hline & Infections & 16.8 & \\
\hline & Dyspareunia & 7.2 & \\
\hline & Perforation & 5.8 & \\
\hline & Urinary problems & 5.3 & \\
\hline & Shrinkage & 2.8 & \\
\hline & Recurrence & 2.1 & \\
\hline \multirow[t]{8}{*}{ SUI } & Pain & 34.9 & \multirow[t]{8}{*}[72]{} \\
\hline & Erosion & 31.8 & \\
\hline & Infections & 18.9 & \\
\hline & Urinary problems & 16.0 & \\
\hline & Perforation & 8.3 & \\
\hline & Recurrence & 7.5 & \\
\hline & Dyspareunia & 5.3 & \\
\hline & Vaginal scarring & 1.6 & \\
\hline \multirow{5}{*}{$\begin{array}{l}\text { Breast } \\
\text { reconstructive } \\
\text { surgery }\end{array}$} & Infections & 6.1 & \multirow[t]{5}{*}[73]{} \\
\hline & Seroma & 4.8 & \\
\hline & Hematoma & 9.5 & \\
\hline & Infections & 6.1 & \\
\hline & Capsule fibrosis & 2.2 & \\
\hline Wound healing & $\begin{array}{l}\text { Chronic } \\
\text { infections due } \\
\text { to biofilm } \\
\text { formation }\end{array}$ & 60 & [74] \\
\hline GBR & $\begin{array}{l}\text { Soft tissue } \\
\text { complications } \\
\text { (dehiscence, } \\
\text { exposure, } \\
\text { infections, } \\
\text { abscess) }\end{array}$ & 18 & {$[75]$} \\
\hline
\end{tabular}

presence inside the body always induces the activation of the immune system [3]. Foreign body reaction is a key point when talking about mesh implants, especially about hernia, PFDs and BR. A strong immune reaction could potentially lead to the formation of a fibrotic scar tissue around the implant and to its encapsulation [3, 11]. In the case of hernia and PFDs, an excessive production of fibrotic tissue may cause native tissue erosion with the subsequent extrusion (or migration) of the mesh [3,5]. Moreover, the formation of the fibrotic capsule is often linked to a reduction of the available mesh area, also known as mesh contraction $[5,62]$. Similarly, for breast reconstructive meshes the intense immune reaction may promote capsular contracture, which in turn could result in pain and breast deformation [63].

Infections are usually caused by infiltration of small bacteria $(1-2 \mu \mathrm{m})$ within the pores of the implant [64]. Considering this, it is evident that pores' dimension plays a role in the success of a mesh. Pores should be big enough to also allow the entrance of immune cells [64]. Some of the most frequent infections that may occur during hernia [15], PFDs [64], BR [10] and wound healing [17] management are related to the presence of $S$. aureus, E. coli, or other gram-positive and gram negative bacteria. With particular regards to wound healing, this condition may develop due to the chronic state of inflammation of the wound that could make the tissue more prone to the entrance of bacteria and to biofilm formation (see Fig. 2) [65, 66], thus making the use of dressings a valuable option to counteract it [48]. Porphyromonas gingivalis, Aggregatibacter actinomycetemcomitans and Streptacoccus mutans infections may develop, instead, after the application of dental membranes [7].

The mechanical properties of the employed materials, as well as that of the meshes, could be the cause for a non-constructive integration of the device with the surrounding tissue. Using very stiff polymers could strongly affect the degree of flexibility and pliability of the final product [5]. Moreover, during the treatment of hernia and PFDs the insertion of a rigid mesh may cause stress shielding, a phenomenon characterized by the thinning and erosion of the native tissue, and caused by a biomechanical mismatch between the prosthesis's mechanical properties and those of the tissue $[67,68]$. Likewise, the use of very stiff meshes in GBR for dental applications could potentially lead to the perforation of the gingival tissue with consecutive mesh dehiscence and exposure [69]. On the other hand, absorbable polymers show some limitations as well. Their degradation time not always matches the ingrowth rate of the new tissue, thus causing a loss of mechanical stability due to implant mechanical failure $[5,18]$.

Finally, traditionally employed manufacturing methods, such as knitting, allow the production of meshes with limited customizability and with geometrical and mechanical features that make them unable to replicate the complex tissue environment and to conform to individual patient's anatomy [18].

Considering all these issues, the need for new strategies to implement meshes production has become evident. The encapsulation of drugs, antibacterial agents or bioactive molecules within the implant could be really powerful to help in counteracting infections $[15,17,41]$. Additionally, a mesh made of the appropriate material, with a correct biomechanical behaviour and a proper design, is paramount to ameliorate its inclusion within the body $[41,70]$. 


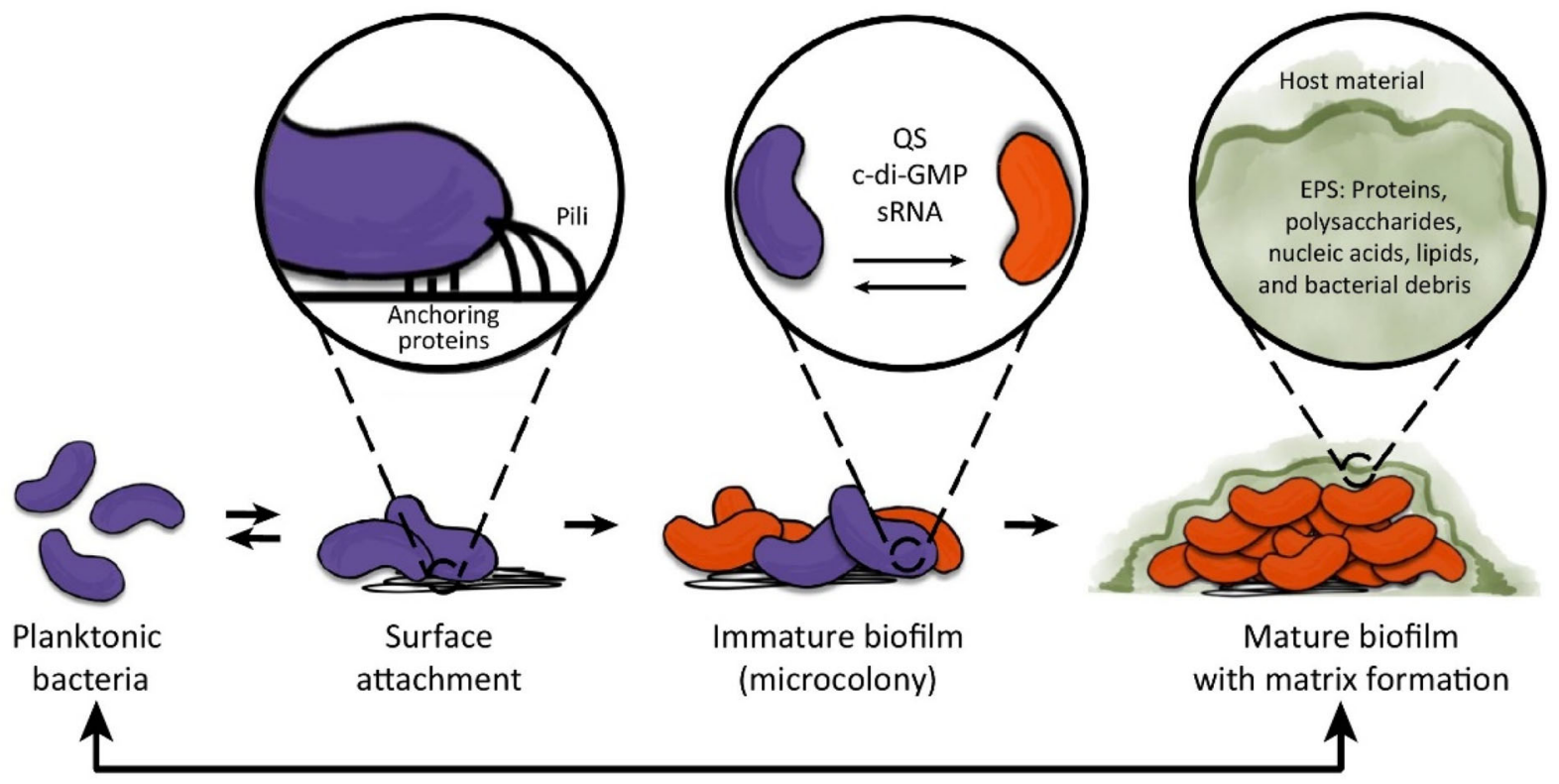

Dispersal and detachment

Fig. 2 Different stages for biofilm formation in chronic wounds. Reprinted from [65], Copyright 2018 Elsevier Ltd

\section{Materials for surgical meshes}

Biomaterials processed as 3D scaffolds are one of the main pillars in tissue engineering-based approach. Scaffold properties, in terms of biocompatibility, biodegradability and biomechanical behaviour, strictly depend on its design, architecture, porosity and pore size, and on the biomaterial(s) choice [76]. In this manuscript, materials will be categorized into synthetic and natural. A further distinction will take place for synthetic materials, since they can be divided into absorbable and non-absorbable. A summary of the materials currently used, as well as possible future choices, is provided in Table 3.

\section{Non-absorbable synthetic materials}

Up to now, non-absorbable synthetic materials are the gold standard for biomedical applications in which meshes are used to provide additional mechanical support to the tissue. This is mainly due to their durability and mechanical features. In fact, mechanical strength and relatively long degradation rates are desirable properties for this type of surgical meshes. High mechanical strength is crucial to properly sustain the tissue, while moderate degradation rates are needed in order to give time to cells to populate the scaffold, produce new tissue while exerting at the same time the requested mechanical properties [42, 96].
According to Baylón et al. mesh implants can be divided into three main material-based categories, with non-absorbable synthetic meshes falling in the first one ("first generation meshes"). Some of the polymers that belong to this category are polypropylene (PP), polyethylene therephthalate (PET) and non-expanded/expanded polytetrafluoroethylene (PTFE/ePTFE) [3]. These materials have been extensively employed in the management of hernia [3], PFDs [5], BR [50] and periodontal GBR [42], with PP being the gold standard in several of these application. Some examples of non-absorbable commercially available mesh are Prolene (Ethicon, PP, hernia), Marlex (Bard, PP, hernia), Marsilene (Ethicon, PET, hernia), DualMesh (Gore, ePTFE and PTFE, hernia) [18], Gyenecare (GynemeshJ\&J, PP, PFDs), Upsylon ${ }^{\mathrm{TM}}$ Y-mesh (Boston scientific, PP, PFDs) [5], Cytoflex ${ }^{\circledR}$ Tefguard (Unicare Biomedical, PTFE, GBR) [7], Gore-Tex ${ }^{\circledR}$ (Gore-Tex ${ }^{\circledR}$, ePTFE, GBR, PFDs) [5, 7].

Recently, thermoplastic polyurethane (TPU), which combines properties of thermoplastics and rubbers, have also gained attentions, especially in the treatment of PFDs [97] and breast implants [98] mainly because of its biocompatibility, flexibility, haemocompatibility and easy processability. Thanks to its mechanical properties, it could be a good choice to potentially reduce mesh-related complications [19].

Aside from polymers, the excellent mechanical features, lightweight properties and ability to withstand inflammations of titanium have been investigated to design meshes for 


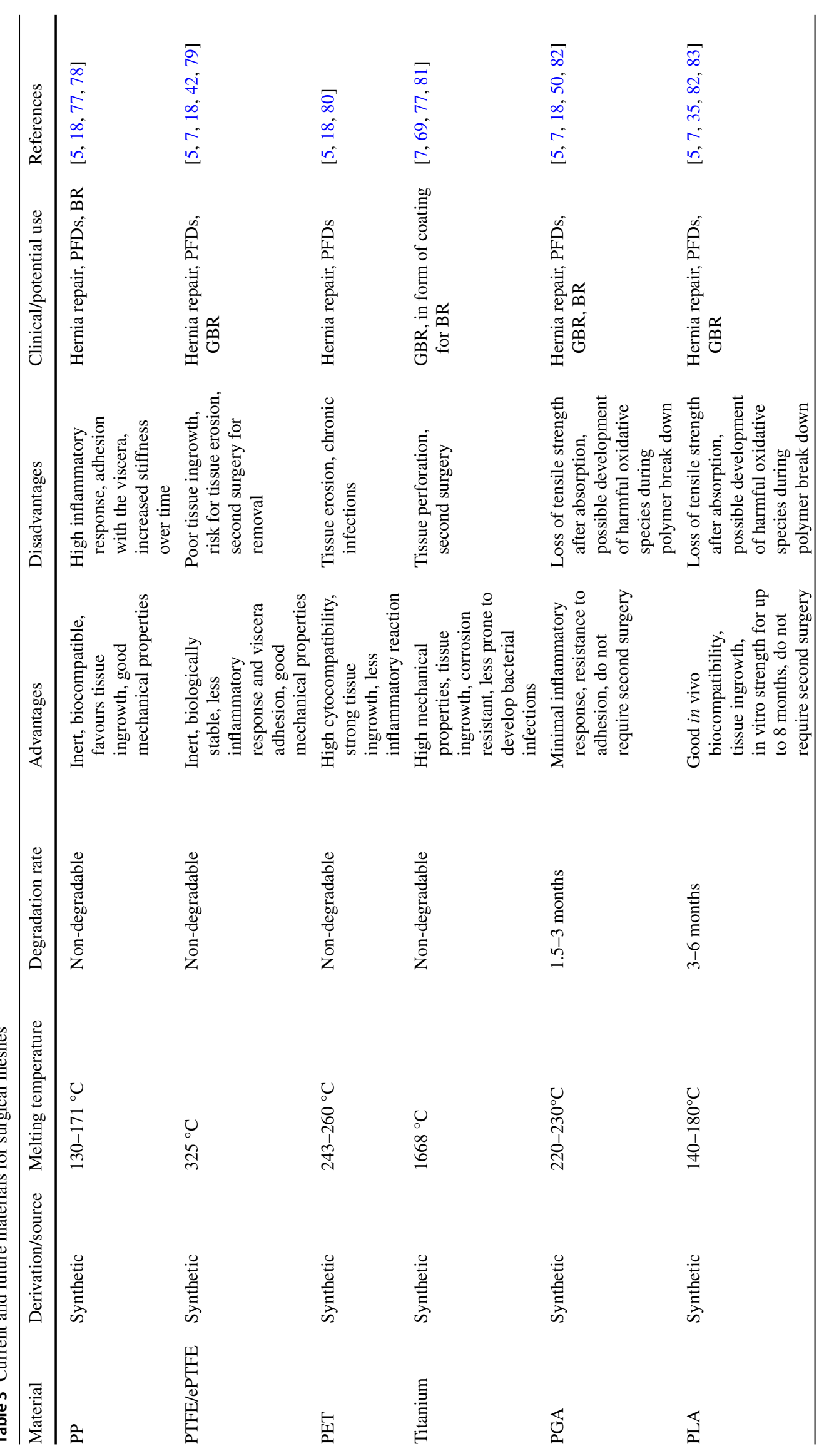




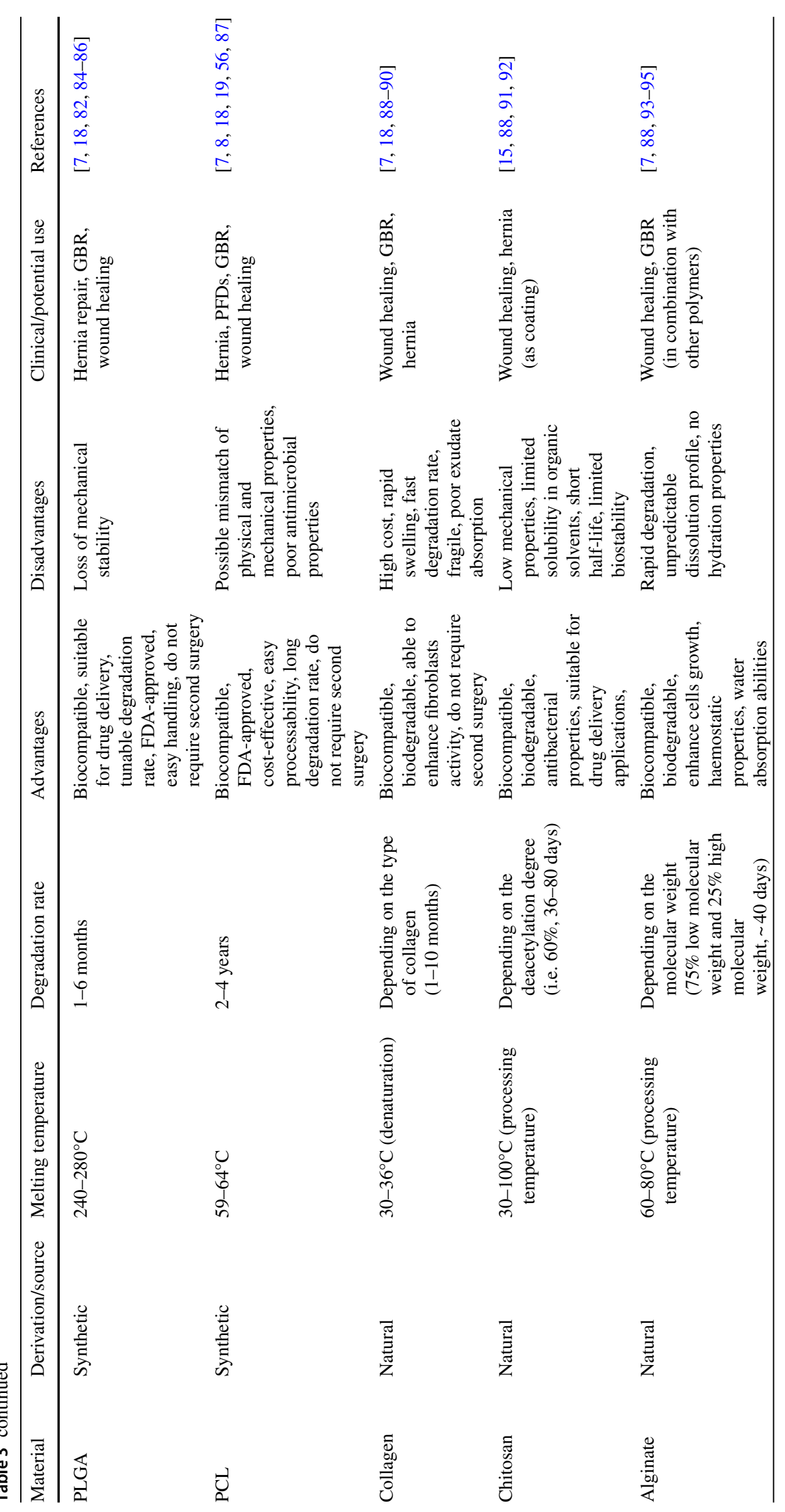


hernia [99], BR [77] and GBR [69]. According to the categorization made by Baylón et al. titanium-coated implants fall into "second generation meshes" category [3]. In a clinical trial by Eichler et al. the performances of TiLoop Bra/TiMesh ${ }^{\circledR}$ (pfm medical ag, Köln, Nordrhein-Westfalen, Germany), a titanium-coated PP mesh for BR applications, were compared with the commonly used acellular dermal matrix (ADM) by analysing their clinical outcomes and the respective arising of complication rates. The study did not show any significant difference between the two devices [77]. Moreover, titanium-coated PTFE meshes have been also used as dental membranes and thanks to their higher compressive strength, they resulted in better outcomes in respect of noncoated PTFE meshes [42].

Unfortunately, despite their optimal mechanical behaviour, the use of non-absorbable meshes is often accompanied by an excessive immune reaction that results in a non-constructive remodelling of the tissue [19], adhesion to the viscera, erosion, [5] infectious complications [100] and, in the case of periodontal GBR membranes, a second surgery for removal [42].

\section{Absorbable synthetic materials}

To overcome the problems related to the permanent presence of a mesh inside the body, absorbable synthetic polymers seemed to be a good choice. They could be used both as coatings, to ameliorate the interaction between the implant and the body and possibly confer antibacterial properties [101], but also as main mesh backbone, since they will eventually degrade, and ideally leaving behind a new and healthy piece of tissue [5].

Polylactide acid (PLA) and polyglycolide acid (PGA), as well as poly(lactic-co-glycolic acid) (PLGA) that is the polymer obtained by their combination, have been widely used in many biomedical applications and for the formulation of drug delivery systems. PLGA demonstrated to be extremely suitable for tissue engineering and drug delivery applications thanks to its tunable degradation rate (that depends upon the molecular weight of the co-polymers), high biocompatibility, easy handling and FDA approval [84]. One of the main fields of application of these polymers is in wound healing, very often used in form of fibrous dressing (this will be further analysed in the next sections), but also in form of drug-loaded nanoparticles to be used as coating for wound mats. For example, Choipang et al. designed a polyvinyl alcohol (PVA) hydrogel coated with ciprofloxacin-loaded PLGA nanoparticles to treat pressure ulcers. The authors performed drug releasing test, noticing a sustained release for up to 6 days with an initial burst release; they assessed the antibacterial activity against $S$. aureus and E. coli and cytotoxicity using dermal fibroblasts. At a PLGA/Ciprofloxacin nanoparticles concentration of $244 \mathrm{mg}$, bacterial growth was reduced of $\sim 99 \%$ in both bacterial colonies, also non-cytotoxic effects were observed [85]. PGA, PLA and PLGA were also used in the design of hernia, PFDs, BR and GBR meshes. Some examples of available meshes are Dexon (Davis and Geck, PGA, hernia and PFDs) [5, 18], Vicryl (Ethicon, Polyglactin 910 [92\% glycolide, 8\% lactide], hernia, PFDs and BR) [5, 6, 18], Polylactide mesh (Ethicon, Polylactide [95\% lactide, 5\% glycolide], hernia) [18]; Guidor (Sunstar, PLA) and Cytoflex Resorb $^{\circledR}$ (Unicare Biomedical, PLGA, GBR) [7].

Polycaprolactone (PCL) is an absorbable polymer whose features are very attractive in tissue engineering field, since it is biocompatible and biodegradable; it can be solubilized in a variety of solvents for fabrication (e.g. chloroform and tetrahydrofuran), is inexpensive and FDA-approved. It has a relatively low melting temperature, thus resulting in an easy processability through a wide range of manufacturing technologies which required molten polymers (e.g. fused deposition modelling (FDM), 3D Printing or hot-melt extrusion (HME)) [19, 87]. Additionally, PCL has a long degradation rates due to the absence of suitable enzymes within the human body, thus slowing down the absorption process [87]. This makes PCL very good for drug delivery since it permits to better control the medication releasing process; moreover, it can be easily combined with other polymers in order to obtain composites with very different properties (e.g. faster degradation rates) that could potentially fulfil the most different needs [19]. Despite this advantages, there are very few commercially available meshes made of PCL or composites of PCL (such as Vivosorb ${ }^{\circledR}$ (Polyganics), Poly-DL-Caprolactone [PDLLCL], used in GBR applications [7]), but many research groups are now investigating the possibility to produce surgical meshes and dressings by using it. For example, Ebersole et al. assessed the effectiveness of PCL nanofibrous meshes for hernia repair applications. They tested six different electrospun meshes obtained by varying PCL polymeric content and processing conditions (flow rate: $3.5 \mathrm{~mL} / \mathrm{h}-10 \mathrm{~mL} / \mathrm{h}$ ), aiming to evaluate their morphology and mechanical behaviour and concluding that high PCL content $(12 \% \mathrm{w} / \mathrm{v})$ and low flow rates $(4 \mathrm{~mL} / \mathrm{h}, 6 \mathrm{~mL} / \mathrm{h})$ was the most promising combination [102].

However, meshes based on absorbable polymeric materials have showed several issues, especially with regards to hernia and PFDs. In fact, due to polymer degradation, it is very likely that the use of these implants is accompanied by loss of tensile strength and subsequent mechanical failure [5]; additionally, rapid absorption rates could potentially lead to the formation of a very poor scar tissue [62].

\section{Absorbable natural materials}

Collagen, chitosan and alginate are among the most exploited natural-derived biomaterials. Collagen is an abundant structural protein present in the human body with the ability 
to enhance fibroblasts functions [88]. Chitosan is a substance derived from the deacetylation of chitin, present in fungi's exoskeleton. It naturally possesses antibacterial activity, promotes drainage, avoids the production of exudates and allows gas exchange [17, 88]. Alginate is obtained from seaweed; it is highly absorbent and biodegradable [93]. These materials could be engineered to produce a wide range of biomedical devices, but very often are used in form of hydrogel, and due to their high biocompatibility and ability to absorb liquids, they have been extensively employed in wound healing applications $[45,88]$. These three materials were also combined by Xie et al. to successfully create a composite seawater-resistant wound dressing, that showed an enhanced ability to promote the healing process while absorbing exudates, facilitating platelet aggregation, clot formation, fibroblasts and endothelial cells migration, keeping a moist environment and protecting the wound [103]. Aside of wound healing applications, collagen's properties have also been exploited in periodontal GBR [41]. For instance, BioMend $^{\circledR}$ and BioMend ${ }^{\circledR}$ Extended TM are bovine-derived type I collagen membranes for GBR that have been developed by Zimmer Denta Inc [104].

To improve the integration of non-absorbable meshes within the body and to reduce the related side effects, in the last years natural materials have been also adopted as coating agents [101]. Collagen, chitosan, cellulose and other ECM components are among the most used [3, 18]. The behaviour of a chitosan-coated PP meshes was investigated by Udpa et al. The authors observed a superior attachment of myoblasts with respect to fibroblasts, which led to the formation of a functional muscular tissue. Also, even if neutrophils were anyhow recruited, they resulted to be inactive, leading to the arising of a very gentle immune reaction [105].

Faulk et al. investigated the long-term in vivo (rat model) remodelling in response to the adoption of an ECM-coated PP mesh for hernia application, in terms of both biochemical and biomechanical feedbacks. Their results confirmed the efficacy of ECM-coating in respect of uncoated devices; particularly, at 14 days post-implantation the macrophages response was mild and after 180 days collagen deposition was minimal [106].

\section{Grafts}

According to the Baylón classification, third-generation meshes include biologic prostheses also called grafts [3]. Biological prostheses are natural and highly biocompatible meshes that could be easily populated by cells and then degrade to leave new tissue [3]. Grafts can be divided into three categories according to their origin [18]: autografts (autologous pieces of tissue), allografts (human-derived cadaveric pieces of tissue) and xenografts (animal-derived pieces of tissues) [107]. Allograft and xenografts are obtained by dermis decellularization in order to remove cells from the tissue, leaving just the organized collagen architecture (ECM) and producing a structure that can be generally called ADM [10]. These types of matrices have been very often used in hernia [18], PFDs [108], BR [100] and wound-healing applications [93] aiming to reach an integration level of the prosthesis with the native tissue with minimal or nonnegative response. Some of the most common source of ADM are rectus fascia, fascia lata [109], human dermis, porcine dermis and porcine small intestine submucosa (SIS) [3]. Aside from dermal substitutes, epidermal grafts have also been used for wound-healing applications. While the use of ADM requires a pre-decellularization of the dermis, using epidermal substitutes requires keratinocytes expansion and cultivation [93]. Even if there are reported advantages related to the use of grafts, such as rapid host revascularization and cell repopulation [10], there are also several drawbacks, which include limitations related to the donor site and tissue harvesting, and post-surgery pain in the case of autografts, possibility to develop infections and prion disease in the case of allografts and xenografts [108, 110].

\section{Drug-eluting surgical mesh implants}

Lately, drug-eluting implants have gained great attention due to the numerous advantages with respect to older ways of drug administration and diseases management. One of the most important advantages is the possibility to sustain and control the medication release for long periods without affecting the drug stability [111]. Due to different fields of applications of surgical meshes, the most suitable drugs to use may vary according to the specific disease. However, it could be possible to differentiate these drugs into antibiotics, antimicrobials agents and nature/biology-derived antibacterial molecules. Therefore, this section will cover a general overview of some of the most used drugs and antimicrobial agents for drug-eluting antibacterial meshes.

\section{Antibiotics}

Antibiotics have been extensively used for bacteria-specific treatment [112]. Rifampicin is a semi-synthetic antibiotic that exerts activity against a wide range of bacteria, among which S. aureus [113]. It has been exploited with promising results by Reinbold et al. to prepare rifampicin-loaded PLGA microspheres to be used as coating for surgical mesh in hernia management. Meshes treated with the new coating material exerted a prolonged drug release profile (60 days) and an antibacterial activity which lasted 30 days [114]. Another class of antibiotics very often used is fluoroquinolones (e.g. ofloxacin, ciprofloxacin, levofloxacin), a broad-spectrum antibiotics active against gram-positive and 
gram-negative bacteria [115]. Guillaume et al. investigated the antibacterial behaviour of an ofloxacin/PCL-coated PP mesh for soft tissue applications (hernia and PFDs). The device successfully achieved a sustained antibiotic release profile for up to 4 days with no burst release. Antibacterial tests carried on E. coli resulted in a potent antibacterial activity, showing an inhibition zone diameter equal to $39 \mathrm{~mm} \mathrm{[116].} \mathrm{Metronidazole,} \mathrm{instead,} \mathrm{have} \mathrm{been} \mathrm{used}$ to counteract periodontitis-related infections [16]. Another class of very used antibiotics exploited in GBR are tetracyclines [e.g. minocycline (7-dimethylamino-6-dimethyl-6deoxytetracycline)] since they exhibit an anti-inflammatory, antibacterial, anti-collagenase activity, as well as osteoclasts and metalloproteinase inhibition, which is important in bone regeneration applications [117]. In a study by Ma et al. minocycline-loaded chitosan nanoparticles have been incorporated into a collagen/chitosan membrane to be used in GBR treatment. In vitro drug release tests showed that antibiotic release rate was sustained for up to 7 days, with an initial burst release. Antibacterial activity was assessed in vitro against Porphyromonas Gingivalis and Fusobacterium Nucleatum, observing a bacteriostatic rate of $95.3 \%$ and $92.1 \%$, respectively, and higher antibacterial potential with respect to antibiotic-free membranes. In vitro biocompatibility assay (using MC3T3-E1 osteoblasts and L929 fibroblasts) was proven. Finally, from the in vivo studies using a rat model, the membranes' ability to guide bone regeneration was observed, leading to the formation of new bone tissue after 4 weeks [118].

Other antibiotics include gentamicin, which has been adopted against staphylococcal infections, and vancomycin, used as an alternative to treat methicillin-resistant Staphylococcus Aureus (MRSA) [15]. Unfortunately, the increasing employment of antibiotics has gradually led to the development of antibiotic resistance [112]. To enlarge their activity spectrum, multi-therapy, which consist in the administration of a combination of drugs, is a useful strategy [15].However, there is still a strong call for new therapeutic approaches.

\section{Antimicrobial agents}

Metallic nanoparticles (MNPs) could be another solution to confer antibacterial properties to mesh implants. Their mechanism of action is still under investigation, but it is thought by the most that their antibacterial activity could potentially derive from a natural toxicity that arise from nanoparticle surface dissolution or oxidative stress via the production of reactive oxygen species (ROS) on the nanoparticles' surface [119]. The antibacterial behaviour of MNPs-loaded PCL wound dressing was investigated by Muwaffak et al. who assessed the efficacy of silver-loaded (Ag-loaded), zincloaded ( $\mathrm{Zn}$-loaded) and copper-loaded (Cu-loaded) meshes, finding out a higher activity of $\mathrm{Ag}$ and $\mathrm{Cu}$ against $\mathrm{S}$. aureus
[120]. Ions incorporation could be an additional advantage also for meshes intended for GBR procedures. In a review by Florjanski et al. it has been reported that silica and titanium nanoparticles could enhance bone regeneration, while silver has the potential to exert good antimicrobial properties [117]. In fact, the effectiveness of Ag MNPs for GBR was also studied by Chen et al. who tested two different methods to perform Ag MNPs coating (sonication or sputtering) on collagen membranes in order to investigate their antimicrobial activity against $S$. aureus and $P$. aeruginosa, biocompatibility (with C3H101/2 mice embryonic MSC) and bioactivity. Sonication was found to be the most promising method to coat $\mathrm{Ag}$ since membranes obtained in this way showed the most promising results in comparison to sputtering, both in terms of antibacterial behaviour and cytotoxicity at a concentration of $1 \mathrm{mg} / \mathrm{ml}$ sonication coating. Additionally, for both the types of coating methods, superior osteogenic activity and in vitro anti-inflammatory behaviour were observed if compared with the uncoated membranes [121]. Ag was found to be affective also against other bacterial infections very common in periodontitis (Aggregatibacter actinomycetemcomitans and Porphyromonas gingivalis). In fact, in a study by Marques et al. membranes made of natural rubber latex (NRL) and Ag MNPs were developed with promising results in terms of antibacterial activity, cell viability and bone formation. In vitro tests were performed using human deciduous dental pulp-derived mesenchymal stem cells (CDLH1 line) on three different samples (negative control, NRL and NRLAgNP) showing the highest percentage of cell viability (98\%) for NRL-AgNP membranes. Additionally, in vivo studies (Rattus Norvegicus Albinus) were carried on to further investigate the device's cytocompatibility and tissue's immune reaction, demonstrating a reduced inflammation with respect to NRL membranes and GBR properties [122].

In addition to MNPs, antiseptics can be included in the category of antimicrobial agents. Among them, chlorhexidine (CHX) have been employed both in hernia and dental applications, thanks to its activity against gram-positive, gram-negative and anaerobic bacteria, showing promising results [123].

Pérez-Köhler et al. assessed the antibacterial potential of CHX-loaded PP mesh against S. aureus, S. Epidermis and $E$. coli for hernia repair applications. They developed a new coating material made of $N, N$-dimethyl- $N$-benzyl$\mathrm{N}$-(2-methacryloyloxyethyl) ammonium bromide and CHX $(1 \% \mathrm{w} / \mathrm{w})$. The antibacterial activity, as well as drug release rate and cytotoxicity, were tested. Slightly better antibacterial behaviour was observed against S. aureus and S. Epidermis but, in general, no adhesion of bacteria was found onto these meshes. CHX release profile was found to be quicker in the first $5 \mathrm{~h}$ and then slower and sustained up to $72 \mathrm{~h}$. AlamarBlue ${ }^{\circledR}$ assay showed no cytotoxicity; however, a reduced fibroblasts metabolic activity was observed 
[123]. The efficacy of chlorhexidine as antibacterial agent in dental applications is well known. Inoue et al. produced a CHX-loaded periodontal membrane made of bacterial 2,3 dialdehyde cellulose and cyclodextrin, showing a prolonged release (even with a burst release at the beginning) and adequate activity against $S$. aureus, E. coli and C. albicans [124]. However, MNPs, as well as antiseptics, may possess some drawbacks, such as toxicity [119] and possibility to develop allergic reactions [125].

\section{Naturally derived antimicrobial agents and biomolecules}

In order to achieve a better integration of the mesh implant with the surrounding tissue and with less cytotoxic effects, biology/nature-based antimicrobial molecules are up-andcoming. Honey, essential oils, chitosan and plant-derived substances are just few examples, often employed in wound healing applications. For example, Wang et al. combined the antimicrobial features of chitosan and honey with gelatine, at different concentrations, in order to create a hydrogel to be used in the management of burns. Antibacterial assay showed that the best outcomes were obtained for the hydrogel composed by $0.5 \mathrm{~g}$ of chitosan, $20 \mathrm{~g}$ of honey and $20 \mathrm{~g}$ of gelatine, with a bacterial growth inhibition rate equal to $100 \%$. The synergistic activity of the employed substances contributed to create an acidic environment able to entrap and neutralize bacteria. Additionally, toxicological analysis and in vivo studies (rat model) demonstrated the hydrogel's higher wound closure percentage in respect of commercially available dressings $\left(\mathrm{MEBO}^{\circledR}\right)$ [126].

Mancuso et al. developed a PCL fibrous antibacterial mesh for soft tissue application by layer-by-layer deposition of Manuka honey (see Fig. 3). Results showed that the addition of Manuka honey to the formulation did not alter the physico-chemical properties of the scaffold and the layerby-layer functionalization allowed its controlled release from the PCL fibres. The implant showed good cytocompatibility and proliferation for fibroblasts (human telomerase reverse transcriptase immortalized fibroblasts from non-malignant myoma, healthy skin human fibroblasts) and endothelial cells (primary human umbilical vein endothelial cells), and a concentration-dependent antimicrobial activity against $S$. aureus, E. coli and P. aeruginosa [127].

Another promising approach to ameliorate the interaction between the surgical device and the human body is to include growth factors within the implant. For example, bone morphogenetic protein (BMP) and platelets have been successfully used in the treatment of periodontitis [16]. In a clinical study by Jung et al. the performances of rhBMP2-coated membranes were assessed in 11 patients after a 6-month period. Hystomorphometric analysis results showed $37 \%$ of newly formed bone at the treated site and $76 \%$ of mature lamellar bone [128]. Ansarizadeh et al. designed a new platelet-rich fibrin (A-PRF)-loaded scaffold made of chitosan and collagen. Mechanical properties, degradation rate, cell viability (using mouse bone marrow mesenchymal stem cells (MSCs)) and osteogenic activity were investigated. The authors modelled the young modulus, the degradation rate and cell viability as variables dependent upon chitosan, collagen and A-PRF concentration, using a polynomial equation. From the performed experiments and numerical simulation, the optimal membrane composition was found to be the one made of a chitosan/collagen weight ratio equal to 4 and a A-PRF concentration equal to $0.58 \mathrm{mg} / \mathrm{ml}$ [129]. In a study carried on by Wang et al. fibroblast growth factors (FGF) were grafted, via oxygen plasma treatment, onto the surface of a fibrous poly-L-lactic acid (PLLA) mesh. The device, to be used in PFDs treatment, showed improved biocompatibility, collagen deposition and cells attachment, and less inflammatory response compared to untreated PLLA. Also, grafting via plasma treatment did not alter its mechanical properties [130].

\section{Manufacturing}

The encapsulation of antimicrobial agents and drugs is just one of the possible approaches that could be exploited in order to produce meshes with antibacterial properties. Another way of proceeding could be "simply" based on the correct selection of the material, as well as the choice of the most suitable mesh design (i.e. morphological properties) [15]. To be effective against infections, mesh implants should possess a pores' dimension much larger than $75 \mu \mathrm{m}$ (macroporous meshes), so that to allow the entrance of bacteria, as well as of immune cells [131]. Additionally, macroporous mesh implants have shown a better response in terms of scar formation, resulting in less production of non-functional fibrotic tissue with respect to meshes with small pores (microporous) [70].

Another aspect that should be considered is the weight or density of the employed mesh, since it could affect the final biomechanical behaviour. Based on the same raw material (i.e. polypropylene), heavyweight meshes (density $>90 \mathrm{~g} / \mathrm{m}^{2}$ ) have proven to be stiff and often microporous, on the other hand, lightweight meshes (density $<50 \mathrm{~g} / \mathrm{m}^{2}$ ) are more flexible, while still exerting mechanical strength, and usually macroporous [3, 18].

Finally, filaments types and their spatial organization could strongly influence the outcomes. It has been proven than multifilament meshes are more prone to develop bacterial infections and less responsive in terms of cellular ingrowth [108]. Moreover, it is well known in tissue engineering that fibres orientation is a factor that strongly influences 
A
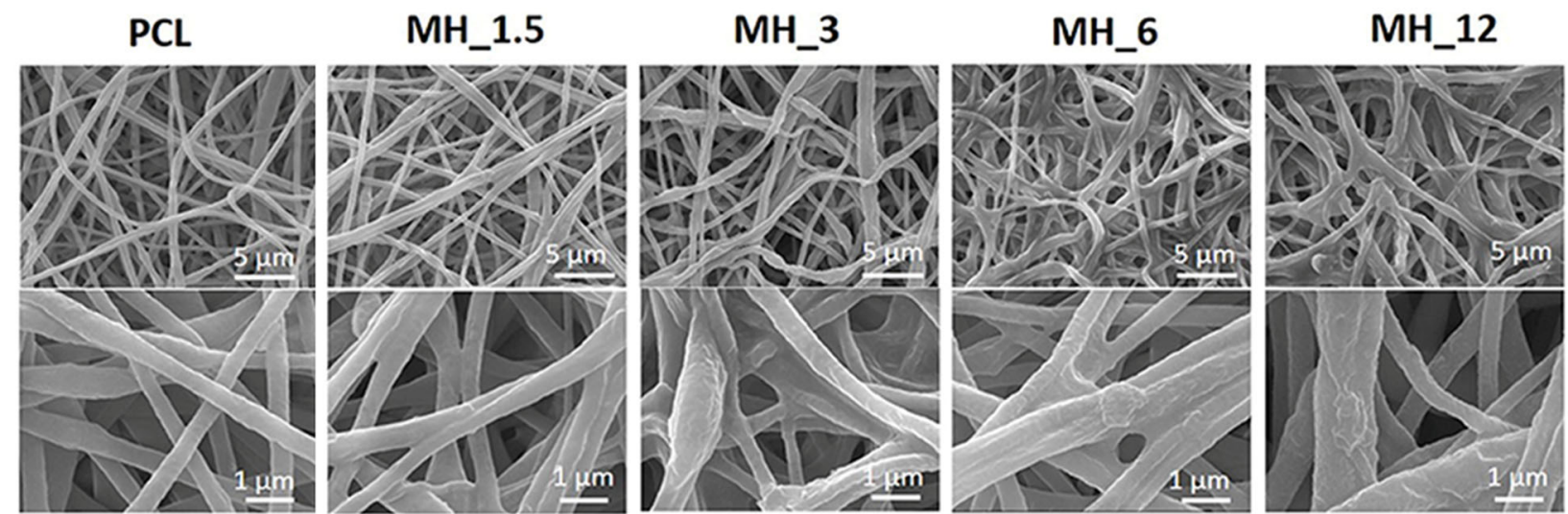

B
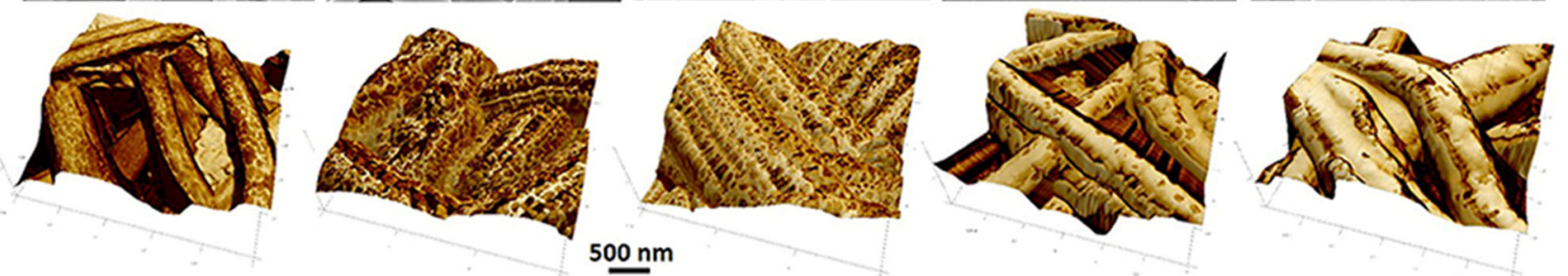

Fig. 3 a Scanning electron microscopy (SEM), b atomic force microscopy (AFM) images of LbL-functionalized PCL electrospun meshes by using Manuka honey (MH) as polyelectrolyte at different concentrations (1.5, 3, 6 and $12 \% \mathrm{w} / \mathrm{v}$, respectively). Reprinted from

the interactions between the native tissue and the implant [132].

In order to satisfy these requirements, in addition to material selection, the adoption of the most fitting manufacturing method is crucial to produce patient-specific mesh implants, with tailorable physicochemical and biomechanical properties. Among these technologies, electrospinning allows to manufacture fibrous architectures with very good ECM-mimicking abilities, as well as topical drug delivery systems (DDS) [133]. On the other hand, additive manufacturing (AM) could be successfully employed in meshes production to create customized drug-eluting devices with pre-determined and reproducible morphological features [134]. These manufacturing methods allow to overcome the widely reported limitations of traditional approaches, including knitted and woven techniques. Poor customisability and especially the inability to resemble the biomechanical properties of the native tissue have been the main drawbacks of knitted meshes. Additionally, the high number of post-operative complications arising from the use of knitted meshes is another limiting factor of this traditional method [3, 18]. Therefore, new manufacturing approaches have been recently introduced, aiming to produce patientspecific custom devices with tailorable biomechanical as well as functional properties (i.e. antibacterial and/or bioactive potential). Table 4 provides an overview of the main materials, medications and manufacturing methods exploited to produce surgical meshes.
[127], Copyright 2019 Mancuso, Tonda-Turo, Ceresa, Pensabene, Connell, Fracchia and Gentile under Creative Commons Licence CC BY 4.0

\section{Electrospinning}

Electrospinning is one of the most employed manufacturing techniques for the fabrication of drug-loaded devices [135]. It exploits electrostatic forces to produce submicron fibres starting from polymeric solutions (solution electrospinning, see Fig. 4a) or melts (melts electrospinning, see Fig. 4b) [136].

A polymeric jet forced out of a syringe (spinneret) and towards a collector, thanks to the application of a voltage difference. Fibres are formed subsequently to solvent evaporation or cooling down of the melt [137]. To obtain the desired morphological features, in terms of fibres diameter and orientation, it is possible by altering process parameters (e.g. voltage, tip-to-collector distance, polymer feeding rate) and external parameters (e.g. polymeric solution physicochemical properties, ambient temperature and humidity) [138], but also by changing and designing new collectors (see Fig. 4c), which allow the opportunity to produce a wide range of different mesh architectures, including randomly oriented fibres, aligned flat fibres, aligned tubular fibres, etc.[133].

Electrospinning has been extensively used in tissue engineering applications due to the ability to create very thin fibres and fibrous architectures that have proven to properly mimic ECM [139]. Additionally, electrospinning provides also an easy and effective way to encapsulate drugs and molecules within these architectures [133]. Drugs encapsulation can be performed in several ways, such as surface 


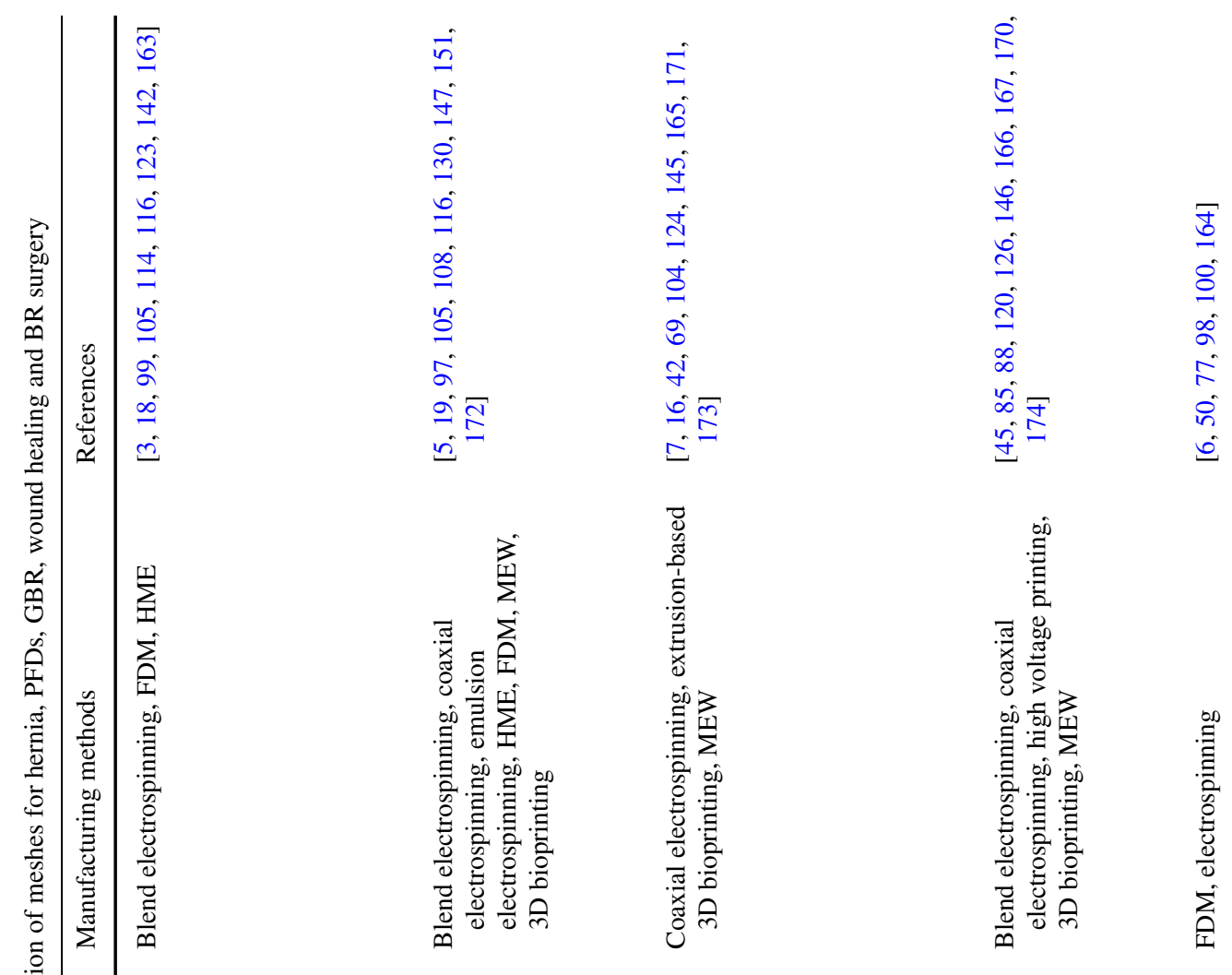

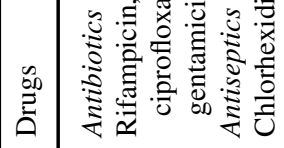
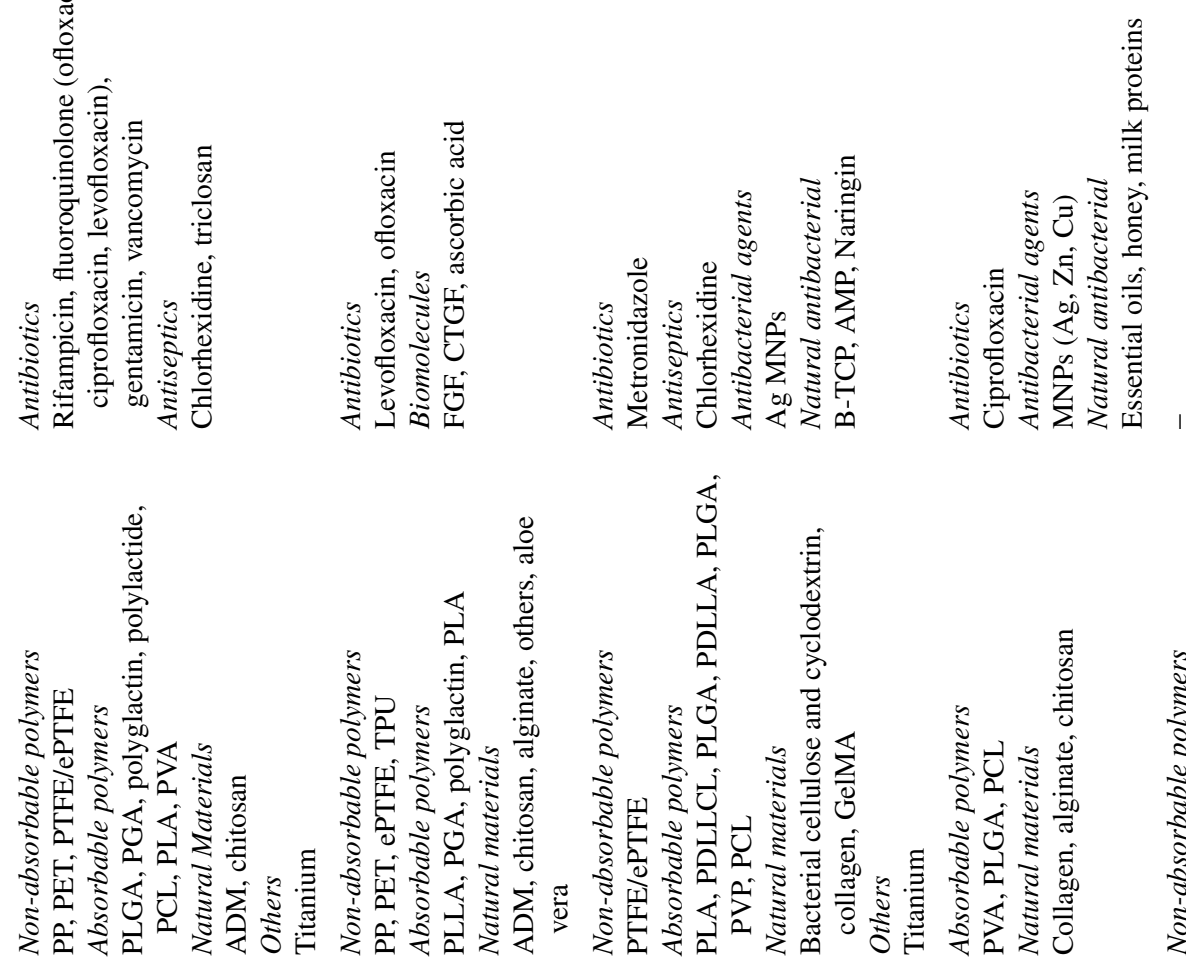

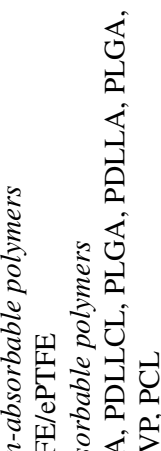

过
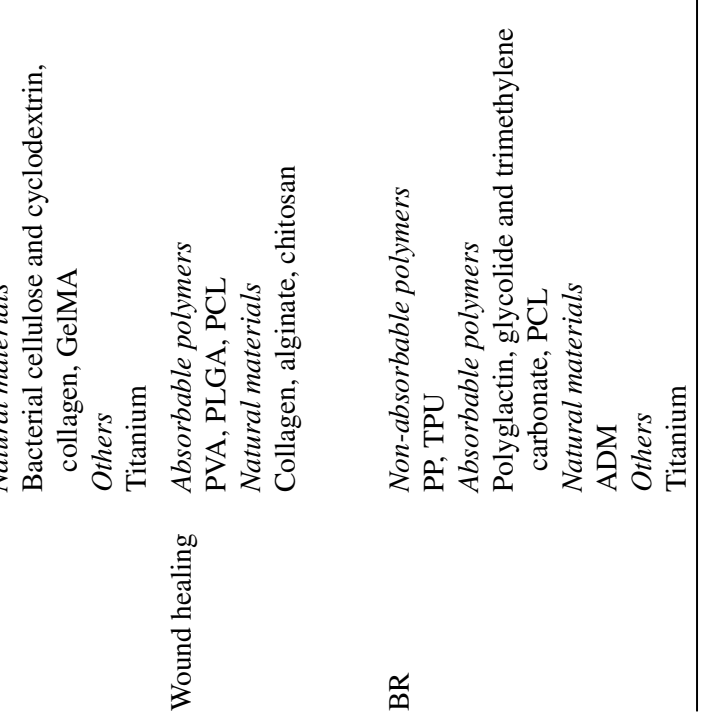

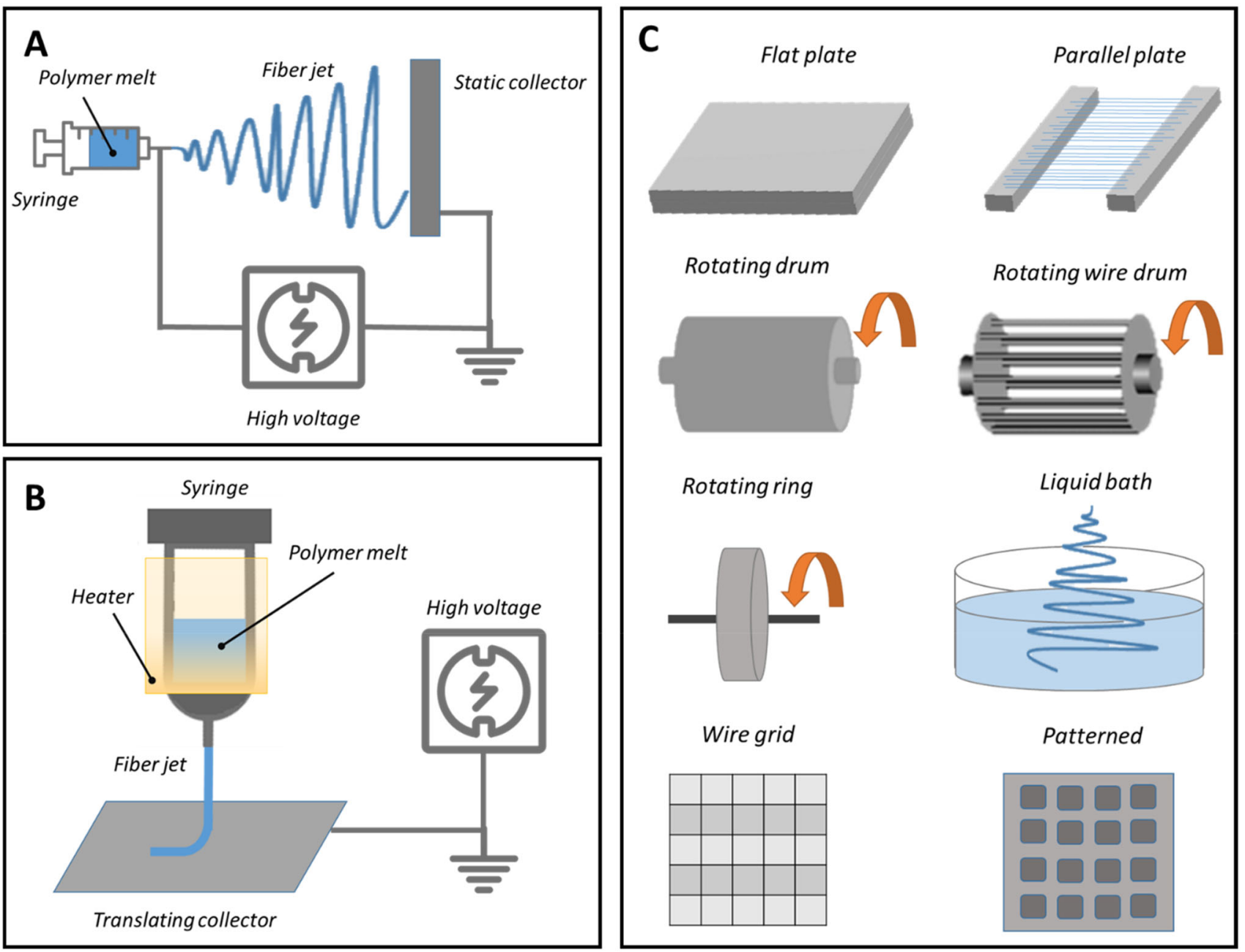

Fig. 4 Schematic representation of a solution electrospinning, $\mathbf{b}$ melt electrospinning setup, $\mathbf{c}$ collector types to influence fibres orientation

functionalization (e.g. coatings, layer-by-layer and grafting), blend, multiaxial and emulsion electrospinning. Coatings, layer-by-layer functionalization and grafting could be successfully employed to load bioactive molecules within the mesh. The main issue with these encapsulation methods is that they are often multiple steps procedures. Conversely, electrospinning allows for the direct inclusion of medications during the spinning process [133].

\section{Blend electrospinning}

Blend electrospinning consist in the solubilization (or dispersion) of the bioactive molecules in the polymeric solution to spin [140]. Hall-barrientos et al. carried on several studies about the interactions of electrospun drug-loaded polymeric meshes for hernia repair applications, testing PCL, PLA and collagen [139, 141]. One of their studies provides comparison of PCL and PLA fibrous meshes and evaluation of the biological response and antibacterial activity. The authors tested two different drugs [Irgsan (IRG, triclosan) and Levofloxacin (Levo)] with several mesh combinations (PCL-drug, PCL-collagen-drug, PLA-drug and PLA-collagen-drug). The obtained results showed good outcomes for PLA and PCL meshes and minimal bacterial infection, with higher cells adhesion and proliferation for Levo-loaded PCL meshes. IRG-loaded meshes show a minimal, or even absent, cells attachment and viability [142]. In fact, many research groups now carried out several studies about the safety of triclosan, which is suspected to be dangerous for human health [143].

Electrospun mats have been very widely adopted also in wound healing management, since they not only promote cells adhesion, but also allow gas exchange and fluid absorption. García-Salinas et al. developed a PCL electrospun anti-inflammatory matrix loaded with essential oils [carvacrol (CAR), thymol (THY), tyrosol (TYR) and squalene (SQU)] for wound healing applications, finding that THY-loaded matrices showed the most effective behaviour against inflammations in vitro [20]. 
Even if blend electrospinning is a really easy way to load molecules into fibres, it has some disadvantages, which include possible denaturation of the bioactive substance in presence of solvents, but also a possible non-homogeneous drug distribution within the implant [140].

\section{Multiaxial electrospinning}

Multiaxial electrospinning can be used to reach a control over the medication release from the fibre [136]. It allows the production of core-sheath and hollow fibres by using a spinneret equipped with two (coaxial electrospinning) or three (triaxial electrospinning) concentric needles, through which it is possible to spin different polymeric solutions and drugs at the same time [144]. He et al. designed a dual DDS periodontal membrane via coaxial electrospinning loaded with Naringin (NAR), aiming to promote osteo-differentiation and bone growth, and metronidazole (MNA), to counteract infections. PLGA was used as sheath material to encapsulate MNA, while polyvinylpyrrolidone (PVP) was selected as core material to encapsulate NAR. The device showed an enhanced antibacterial activity against $F$ usobacterium Nucleatum with respect to un-loaded fibres and stimulated cell growth [145]. Prado-Prone et al. also employed coaxial electrospinning for the development of antibacterial wound mat made of PCL (core) and loaded with Zn nanoparticles (ZnNPS) (shell) (Fig. 5). Antibacterial tests were carried on against $S$. aureus and $E$. coli, observing a major activity against gram-positive (S. aureus) bacteria. The effects of UVA light exposure (prior to bacteria inoculation) on mats were studied too, resulting in an even more effective antibacterial activity [146].

Hansesn et al. also tested the performances of coaxial fibres against solid fibres (obtained by blend electrospinning) for PFDs applications. In this study, the performances of PCL hollow and solid fibres, loaded with FGF, connective tissue growth factors (CTGF) and rat mesenchymal stem cells (rMSC) were investigated in vivo by using a rat model. The results highlighted the inability of hollow fibres to provide mechanical support during collagen deposition, due to their fast degradation. In fact, among all the tested meshes, these ones were associated with the highest level of complications (first of all herniation) [147].

\section{Emulsion electrospinning}

Core-shell fibres can be produced by spinning an emulsion rather than a solution [148]. The use of the correct solvents is crucial in both emulsion and multiaxial electrospinning due to the necessity to spin more solutions at the same time. Solvents that do not cause their mutual precipitation are needed, so a good choice could be exploiting immiscible solutions [149]. To stabilize these solutions, the employment of surfactants could be useful [144, 150]; however, their presence may alter the mechanical properties of the final device [151] as well as its adhesion properties [144]. Mangir et al. loaded Lascorbic acid (AA) and ascorbate-2-phosphate (A2P), which have been proven to increase collagen production, into PLA electrospun fibres using emulsion electrospinning. Their aim was to asses any improvements in terms of collagen production and its impact on mechanical properties of the device. The developed mesh actually enhanced collagen production, with slightly better results for A2P releasing mesh, but the mechanical properties were affected by the inclusion of surfactants [151].

All the mentioned techniques are solution-based as all employed polymeric solutions. An important point to consider when using solution-based electrospinning techniques is the toxicity of most solvents used in the process (e.g. chloroform, tetrahydrofuran, dimethylformamide). Using solvent-free configurations, such as melt electro-writing [see "Melt electro-writing (MEW)" section], could be a valuable option [152].

\section{Additive manufacturing}

AM technologies are based on the layer-by-layer building up of the final structure starting from digital data. This information can be obtained through a computer tomography (CT) or magnetic resonance (MRI) and can be subsequently elaborated in order to generate a digital design file by means of computer aided design (CAD) software, thus allowing the creation of complex 3D architectures with predictable geometric features (e.g. pore volume, interconnectivity and distribution) [153, 154] (see Fig. 6) [155]. It has become very attractive in the biomedical field due to its cost-effectiveness, possibility to obtain personalized devices in relatively fast times and to process both composites and biomaterials.

Selective laser sintering (SLS) and stereolithography (SLA) are light-based AM techniques that have been used often in the biomedical field. In SLS, a laser beam is selectively directed on a powder bed to fuse a thin layer of them in the desired shape. The process is repeated layer by layer, and after hardening of the melted powders, a defined 3D structure is obtained. Similarly, SLA uses light to harden photosensible polymers and built 3D objects after a layered repetition of the same process. Even if SLS and SLA proved to be successful in producing biomedical devices, they also present some drawbacks, among which there are high processing temperatures and costs for SLS [156, 157] and a small number of biocompatible photopolymers for SLA [158]. On the other hand, 3D printing is another promising AM technology that have been successfully employed to include bioactive compounds and cells directly during printing (see "3D bioprinting" section) [134, 159]. 

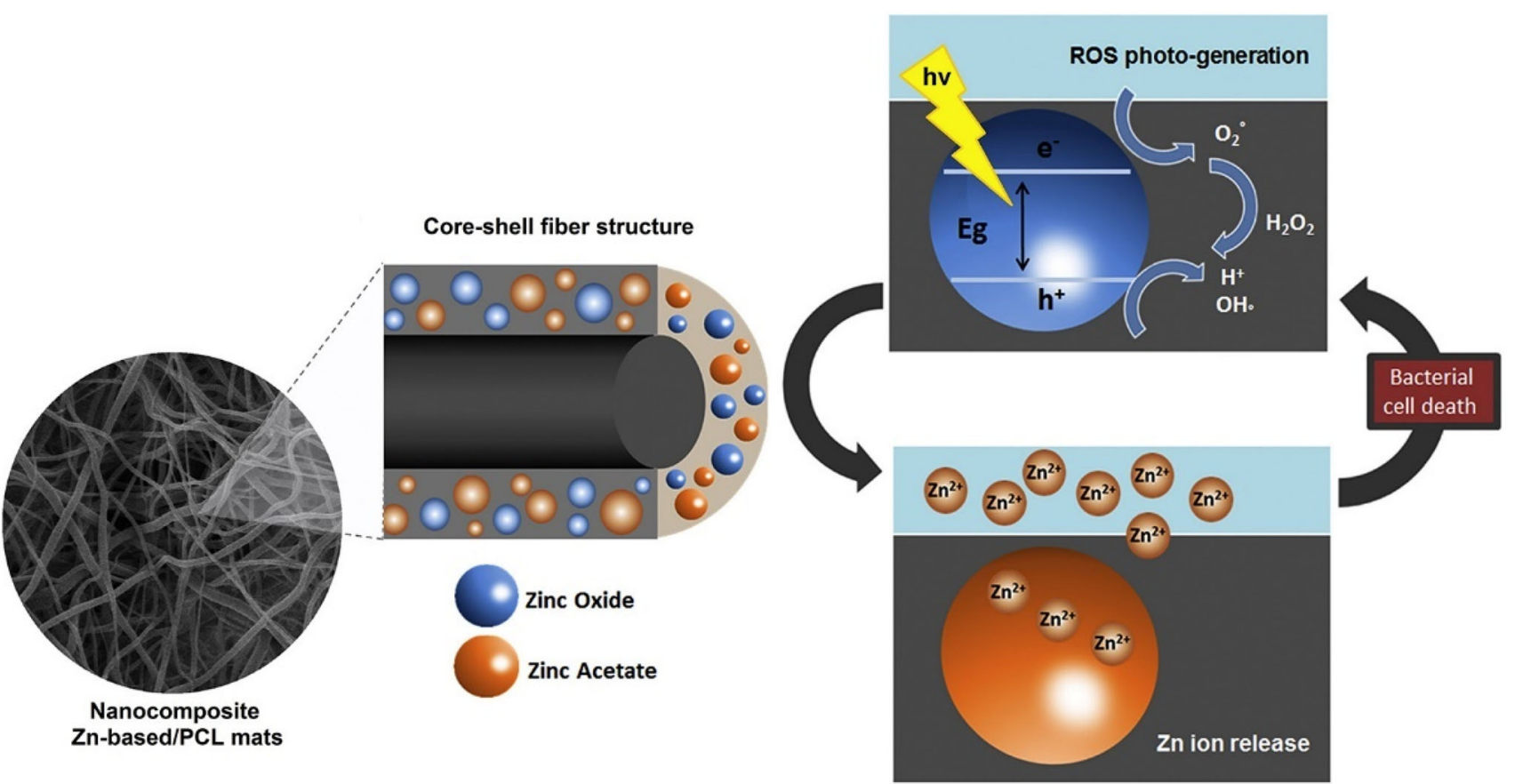

Fig. 5 Zn-loaded PCL coaxial fibres developed by Prado-Prone et al. and their mechanism of action. Reprinted from [146], Copyright 2018 Elsevier Inc

\section{Hot melt extrusion (HME) and fused deposition modelling (FDM)}

HME is based on the extrusion of a polymeric melt, which is forced through a die by means of convey screws, to form a fibre [160]. This technique has been used in pharmaceutics to include drugs within a polymeric carrier [19]. Additionally, HME was the first method employed to produce polymeric meshes, in which filaments, once extruded, were knitted according to a specific pattern [3]. Hot melt extruded drugloaded fibres could also be used as feeding polymer during the printing of implants via FDM (see Fig. 7) [161]. FDM is based on the CAD-controlled layered extrusion of molten polymer fibres [158]. It gained attention because of its ability to print devices with good dimensional precision and quality, while maintaining low cost and reduced times of production [162].

Domínguez-Robles et al. used HME and FDM to produce Levo-loaded TPU filaments that were subsequently employed in 3D printing of meshes for PFDs as shown in Fig. 8. The research group studied the mechanical behaviour of the devices, as well as their antibacterial activity. The final data has proven to be more flexible and less rigid in respect of PP meshes, but also, to be effective against $S$. aureus and E. coli [97].

FDM was also used by Qamar et al. to produce ciprofloxacin-impregnated meshes for hernia repair. Two types of materials were processed (PP and PVA), and meshes were printed with different pore geometries (diamond and square) and dimensions. Their mechanical behaviour, antibacterial activity and in vivo biocompatibility were investigated using a rabbit model. Drug was released in both meshes for almost $7 \mathrm{~h}$, with an initial burst release. Considering that for hernia repair applications, a tensile strength between $16 \mathrm{~N} / \mathrm{cm}^{2}$ and $30 \mathrm{~N} / \mathrm{cm}^{2}$ is required; PVA meshes showed a better biomechanical behaviour compared with PP, since the obtained tensile strength ranged between $17 \mathrm{~N} / \mathrm{cm}^{2}$ and $30 \mathrm{~N} / \mathrm{cm}^{2}$. Additionally, it was observed a greater biocompatibility of PVA devices in respect of PP, with less fibrous tissue and mild immune reaction [163].

Baek et al. used FDM and electrospinning to produce a hybrid PCL scaffold for BR, aiming to improve implanttissue interactions. The device showed enhanced flexibility with respect to ADM. Furthermore, it induced lipogenic differentiation without any foreign body reaction, thus resulting very promising for BR surgery management [164].

A multi-head deposition system was used to combine and print at $135^{\circ} \mathrm{C}$ a blend of PCL, PLGA and $\beta$-tricalcium phosphate $(\beta-\mathrm{TCP})$ to prepare a dome-shaped 3D membrane for periodontal applications. In a study by Shim et al. meshes were subjected to tensile test and in vitro cell proliferation test, in vivo (beagle dog model) clinical setting and were also compared to titanium membrane used in clinics, proving their equal efficacy in terms of bone formation and osseointegration. The results could open the horizon to new frontiers in the use of biodegradable membranes, thus avoiding second surgery [165]. 


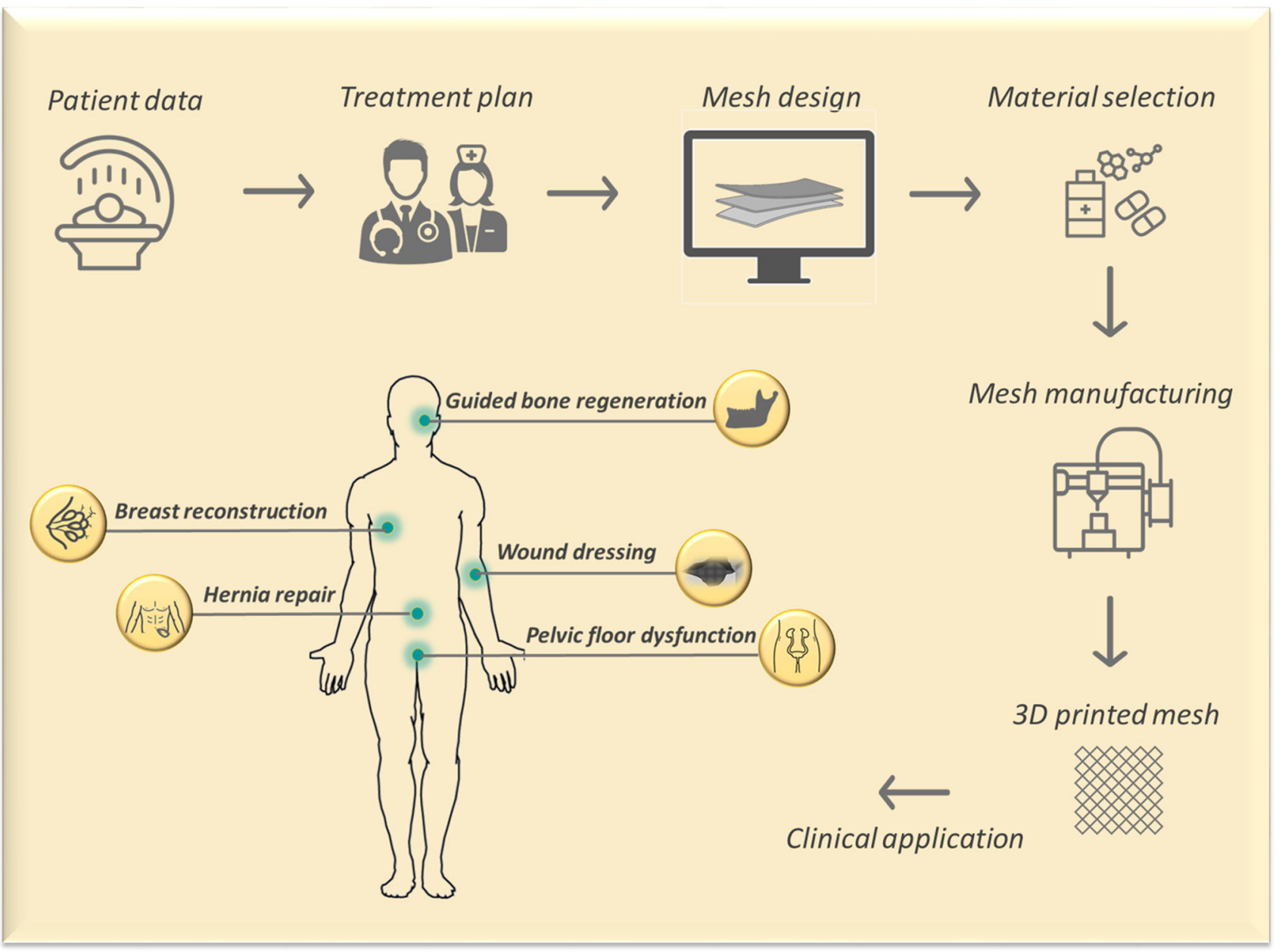

Fig. 6 Additively manufactured surgical meshes workflow: from patient data to clinical application

Due to the high processing temperatures required, only a limited number of polymers (e.g. thermoplastic polymers as TPU and PCL) [134] and drugs can be used to create biomedical implants and devices via FDM [158]

\section{D bioprinting}

Extrusion-based 3D bioprinting received a great attention in tissue engineering because of the possibility to print a wide range of polymeric-based biomaterials, with or without cells, called bio-inks, and often loaded with bioactive compounds [159]. A 3D bioprinter is generally composed by a dispenser (mechanically or pneumatically driven) which is connected to a robotic stage that can move along the three axes $(x, y, z)$, laying down the bio-ink onto a collecting plane, as shown in Fig. 9 [162].

One promising field of application of 3D bioprinting is wound healing. For example, with the intension to recreate the by-layered structure of the skin, Wang et al. combined high voltage printing and $3 \mathrm{D}$ bioprinting to design a bilay- ered membrane scaffold made of PLGA and alginate in which PLGA was used as the superior layer to mimic the epidermis, while alginate was used as the inferior layer to mimic the dermis. The obtained implant provided a moist and insulated environment for the wound. Additionally, it successfully acted as barrier against $S$. aureus; it showed good biocompatibility (with murine L929 cells), and it accelerated wound healing in vivo (rat model, complete healing in 12 days), promoting an initial and constructive inflammation and stimulating vascularization and collagen deposition [166]. Another device was developed by Afghah et al. whose included silver nitrate particles in the formulation to provide antibacterial effects to the dressing. They printed a PCL-block-poly (1,3-propylene succinate) (PCL-PPSu) mats and investigated its degradation rate and hydrophilicity. Moreover, in vitro cytotoxicity assays using human dermal fibroblasts and antibacterial tests against $S$. aureus, $C$. albicans, E. coli, P. Aeruginosawere were carried on. The obtained results made it clear that at a concentration of $1 \%$ $\mathrm{wt} / \mathrm{wt}$ of silver nitrate, the dressing's antibacterial behaviour 

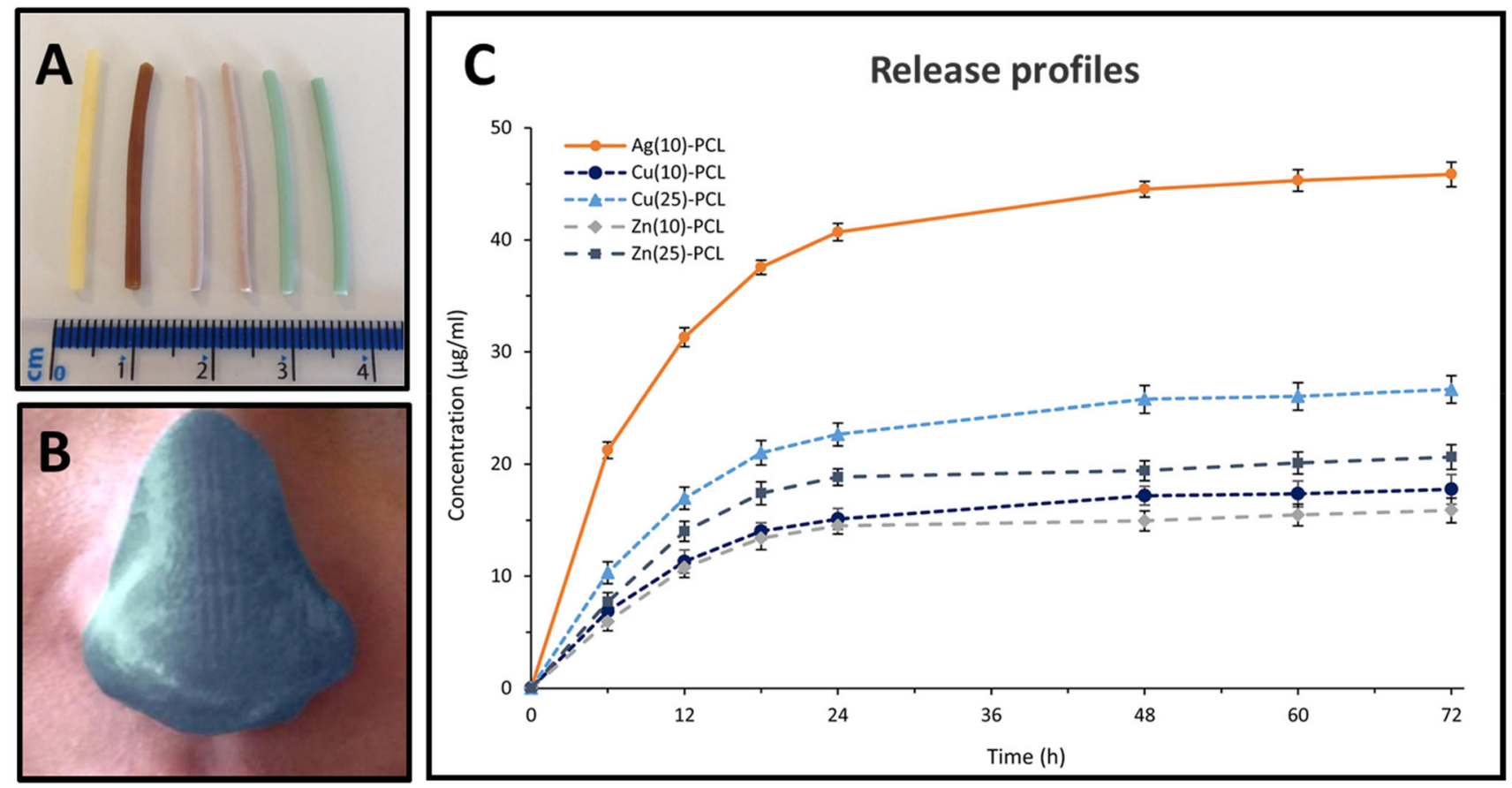

Fig. 7 Patient-specific wound dressings; a filaments loaded with metals, from left to right: plain PCL, $\mathrm{Ag}(10 \% \mathrm{w} / \mathrm{w})-\mathrm{PCL}, \mathrm{Zn}(10 \% \mathrm{w} / \mathrm{w})-\mathrm{PCL}$, $\mathrm{Zn}(25 \% \mathrm{w} / \mathrm{w})-\mathrm{PCL}, \mathrm{Cu}(10 \% \mathrm{w} / \mathrm{w})-\mathrm{PCL}$ andCu (25\% w/w)-PCL; b 3D printed $\mathrm{Cu}-\mathrm{PCL}$ nose dressing; $\mathbf{c}$ release profiles of $\mathrm{Ag}(10 \% \mathrm{w} / \mathrm{w})-\mathrm{PCL}$,
$\mathrm{Cu}(10 \%$ w/w)-PCL, Cu (25\% w/w)-PCL, Zn (10\% w/w)-PCL and Zn (25\% w/w)-PCL in PBS. Reprinted from [120], Crown Copyright 2017 Elsevier B.V.
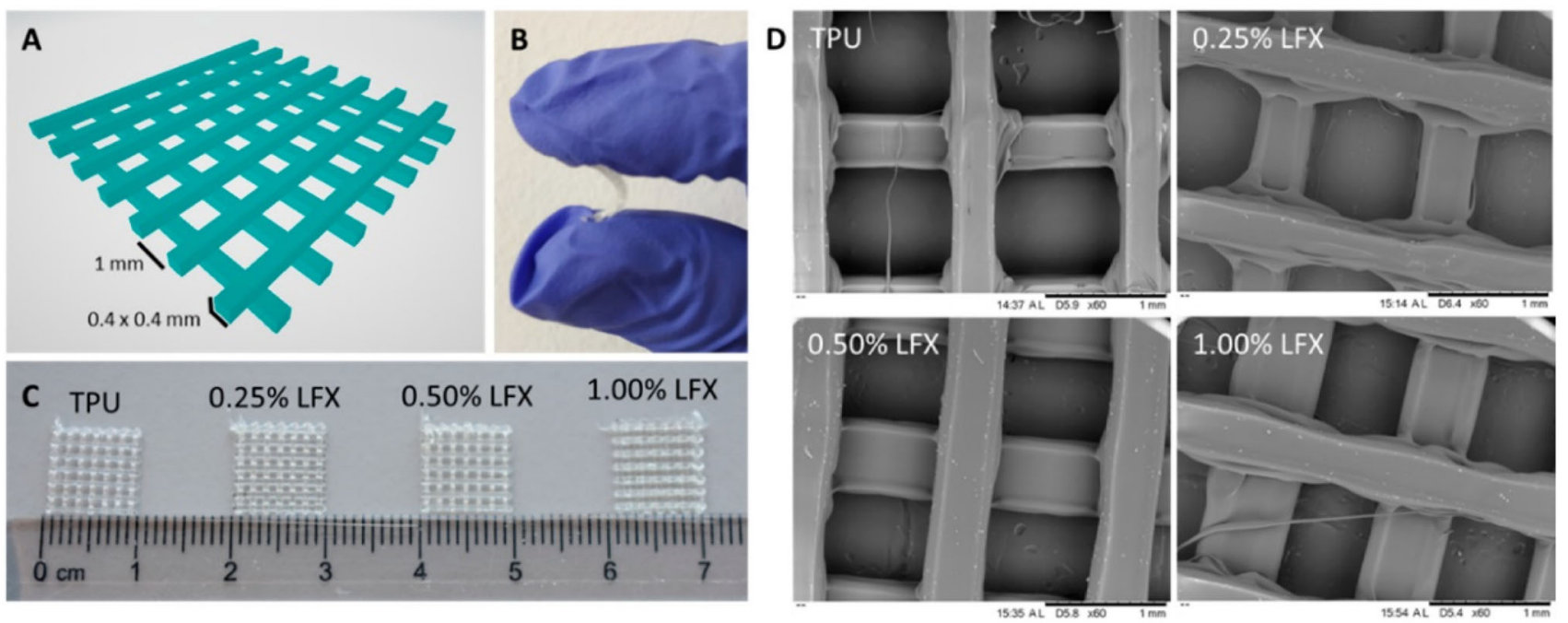

Fig. 8 PFD mesh developed by Domínguez-Robles et al. a CAD project with relative mesh dimension; $\mathbf{b}$ flexibility of TPU meshes; $\mathbf{c}$ Levo-loaded TPU meshes; d SEM images of Levo-loaded TPU vaginal meshes. Reprinted from [97], Copyright under Creative Common Licence CC BY

was significantly enhanced, especially against $E$. coli and $C$. albicans. Also, the inclusion of silver nitrate in the formulation did not alter the cytocompatibility of the used materials [167].

3D bioprinting has greatly evolved towards the production of complex scaffolds; however, it still has some limitations such as low printing speed and needs for complex bio-inks and multi-material architectures. In fact, even considering all the progress done within the bioprinting field, re-creating biological structures can be difficult, since tissues and organs possess way more complicated architectures, with different mechanical properties, sizes as well composition at the cellular level [159]. 


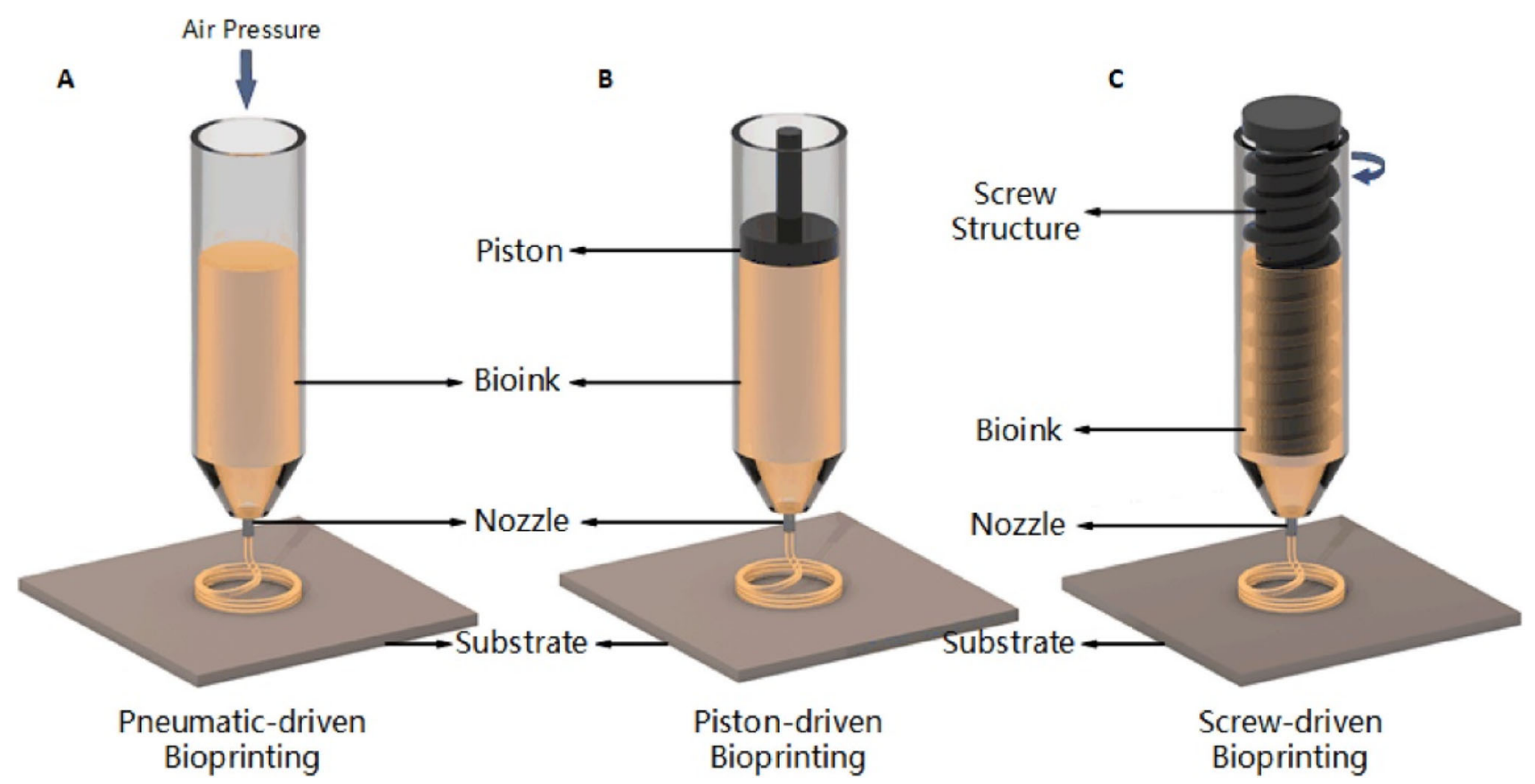

Fig. 9 Schematization of material extrusion during 3D bioprinting: a pneumatically driven; b, c mechanically driven. Reprinted from [159], Copyright 2019 Shenyang Pharmaceutical University under Creative Commons Licence CC BY-NC-ND 4.0

\section{Melt electro-writing (MEW)}

MEW is a manufacturing technology that combined working principles from electrospinning and AM. MEW exploit voltage differences to "write" electrospun scaffolds with predetermined architecture and geometrical features (Fig. 10) [133].

However, there is a substantial difference between solution-based electrospinning and MEW. Electrospinning requires the arising of fluids instabilities (whipping instability) to draw the fluid out of the spinneret and towards the collector. On the other hand, MEW based on the concept according to which the application of an electric field between the nozzle and the collector, stabilizes the jet, avoiding instabilities. This allows to continuously lay down polymeric filaments with different diameter by using low flow rates and just one nozzle [168]. Aside from the electric field, some other parameters must be tuned in order to achieve a controlled and reproducible flow. The feeding rate to the spinneret should match the one of the stabilized polymer jet in order to avoid fibre pulsing, which can cause an unstable flight path. Also, the velocity of the moving collector (the spinneret is fixed) should be higher than the speed of the jet. This velocity is called critical translation speed (CTS): when operating above its value, fibres could potentially reach sub-micron sizes. However, in this condition nonlinear fluid patterns may arise. Thus, the majority of MEW-produced scaffolds possess fibres with a diameter that ranges between $2 \mu \mathrm{m}$ and $50 \mu \mathrm{m}[168,169]$.
MEW could be preferred in respect of solution-based electrospinning, since it allows to produce better fibres both in terms of morphology and drug delivery mechanism (no burst release) [137]. However, it presents some limitations that are mainly due to high processing temperatures, that limits the number of materials and drugs which can be used [137].

Despite its disadvantages, MEW was used by Hewitt et al. to produce a melt electrospun PCL scaffold loaded with milk proteins (MPs) to be used in wound healing applications. Their aim was to assess the feasibility of the manufacturing process and investigate in vitro scaffold's performances (wound healing assay). The authors were able to write PCL/MPs powders blend at a temperature of $85{ }^{\circ} \mathrm{C}$ and obtain good results in terms of both protein release (up to 21 days) and tissue regeneration [170]. Dubey et al. used PCL in the development of a reinforced membrane for GBR. PCL was melt-electrospun and then covered with a layer of Gelatin-Methacryloyl (GelMA) and amorphous magnesium phosphate (AMP). Different combinations of GelMA, PCL and AMP were tested. The authors assessed the physicochemical and biomechanical properties of the devices and their in vivo (rat model) performances, comparing them with GelMA and PCL + GelMA membranes. The results showed that the reinforced membranes possessed high stiffness (can be modulated by altering the chemical composition of the mesh), high rate of mineralization, osteogenic gene expression and in vivo bone formation. Moreover, the presence of the layer of GelMa and AMP reduced the in vivo degradability of the implants [171]. Finally, MEW was combined 

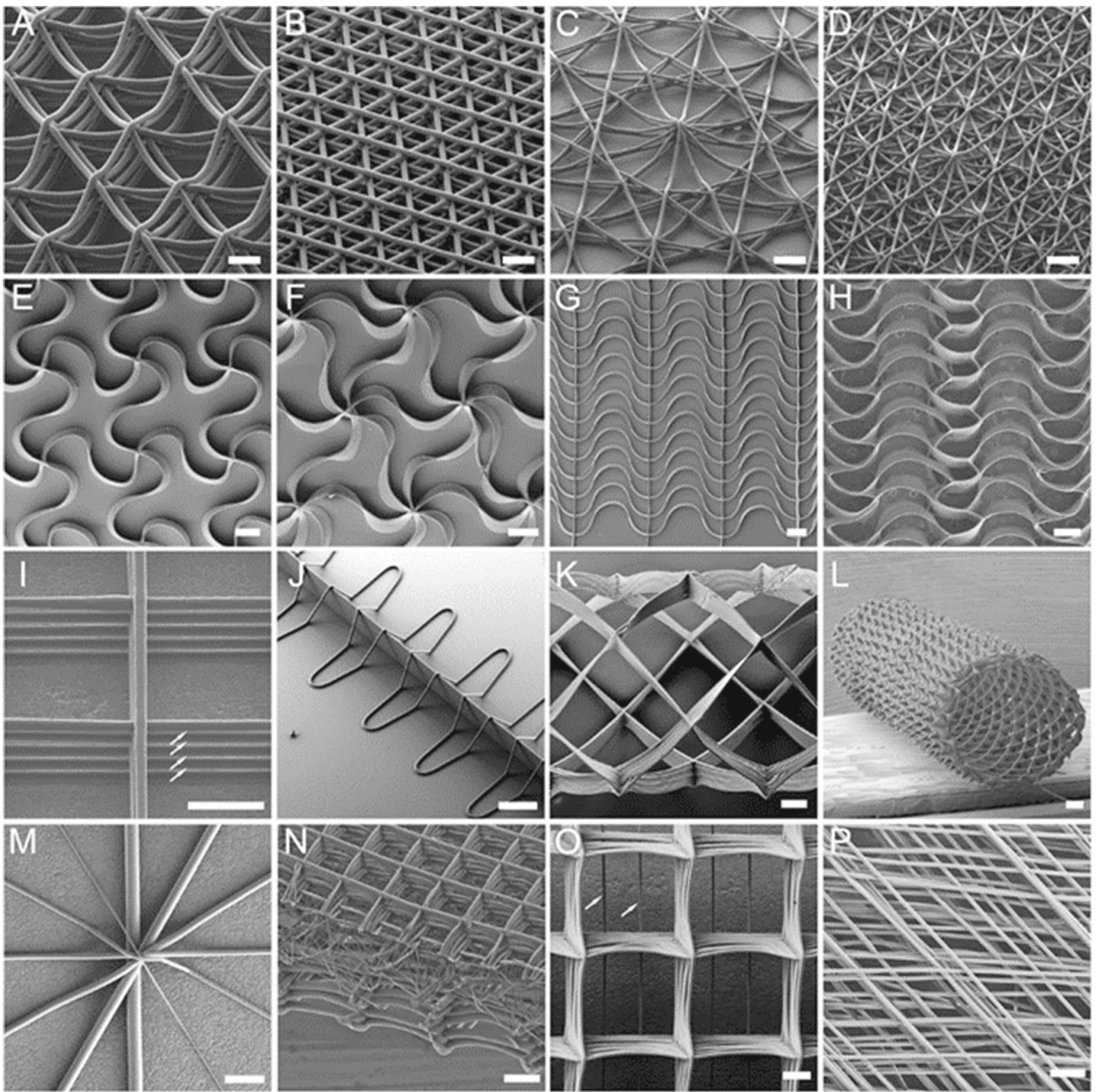

Fig. 10 Examples of different patterns and scaffolds that can be obtained via MEW (scale bars $=100 \mu \mathrm{m} \mathbf{a}-\mathbf{d}, 500 \mu \mathrm{m} \mathbf{e}-\mathbf{h}, 50 \mu \mathrm{m} \mathbf{i}, 200 \mu \mathrm{m} \mathbf{j}-\mathbf{l}$, and $100 \mu \mathrm{m} \mathbf{m}-\mathbf{p}$ ). Reprinted from [169], Copyright 2019 The Authors (Paul D. Dalton, Dietmar W. Hutmacher, Thomas M. Robinson)

with 3D bioprinting to manufacture a melt electrospun PCL mesh for PFDs applications. In a study by Paul et al. meshes produced using MEW were covered with a layer of 3D bioprinted aloe Vera/alginate (AV/ALG) hydrogel loaded with endometrial mesenchymal stem cells (eMSCs) in order to enhance the antibacterial and anti-inflammatory behaviour of the construct. Thanks to its in vivo (mice model) compatibility and tissue integration, this implant could be successfully employed to treat POP by also using autologous eMSCs from the patient [172].

\section{Regulatory considerations}

Due to the high number of post-operative complications, the use of vaginal meshes for the treatment of POP and SUI was reviewed by FDA [175]. The process started in 2011 with a discussion about the effectiveness and safety of these devices [176] and resulted in the withdrawal of some products from the market in 2019 [175].

Recently, new regulations have been adopted by the European Parliament as well as FDA, according to which surgical 
vaginal meshes have been reclassified from class II to class III (high risk) medical devices [177]. PFDs meshes have been discontinued in some countries, such as Australia and New Zealand $[13,14]$ and, as indicated by the National Institute for Health and Care Excellence (NICE), they should be adopted only as last resort, making patients aware of all the possible complications [178]. The use of meshes for the treatment of POP is still ongoing in the UK, although new regulations have been put in place by the Medicines and Healthcare products Regulatory Agency (MHRA). These include a tight postmarketing surveillance of the implants, which is based on the recording of any mesh-related adverse events, via Yellow Card Scheme, as well as the introduction of a periodic summary update reports (PSUR) [179]. Different considerations can be made for graft-derived slings for SUI surgery, since they are still considered as a treatment option in many countries. Specifically, slings derived from autologous or heterologous tissues are actually preferred in comparison to vaginal meshes because of the abundance of positive data collected following their use $[34,180]$ and limited recorded issues post-implantation.

Meshes for hernia have been also subjected to some investigations in order to evaluate their safety and feasibility. In a Cochrane review about the outcomes of groin hernia repair with and without meshes, the superiority of mesh-based treatments in comparison with traditional surgery (in terms of recurrence rate, complication rates, duration of the surgery and post-operative recovery) was concluded [181]. Moreover, in 2019 a review from the Welsh Chief Medical Officer confirmed the safety and the employability of hernia meshes [12]. Regardless, and given the controversial data derived from the use of meshes for PFDs, FDA is continuing specific investigations about the use of hernia meshes, monitoring the outcomes of all the marketed devices and encouraging patients to report any kind of adverse event via MedWatch, which is the FDA Safety Information and Adverse Event Reporting program [182]. Regarding the use of meshes for BR surgery, FDA has started to pay attention also on these types of meshes, although currently there are no regulations in place since more data are needed to establish their feasibility and safety [1].

Wound dressings are subjected to some regulations too; however, these are less restrictive in comparison to those for vaginal and hernia meshes. These guidelines mainly regard honey and silver antimicrobial dressings [183]. Honey dressings must not be used on patients with an extreme sensitivity to honey and bee product in general and should be employed very carefully in diabetic patients [184]. Silver dressings must be used only in case of evident bacterial infection and to treat complicated wounds. Also, due to the possible toxicity of silver [185], they should not be used on acute wounds, on children, during pregnancy and on patients with hepatic or renal impairment [186].
Finally, some important considerations must be done on the manufacturing methods, especially on 3D printing. This kind of manufacturing process has gained great consideration during the last decade and has been successfully used by surgeons to treat some life-threatening conditions. In light of this, FDA is currently working on the definition of guidelines for 3D printed devices, in order to ensure their safety for usage in clinical practice [187]. In 2017, the U.S. Department of Health and Human Services, the FDA, the Centre for Devices and Radiological Health and the Centre for Biologics Evaluation and Research drafted a document with some manufacturing and testing considerations to be followed during the production of a $3 \mathrm{D}$ printed medical devices, which included:

- precise identification of process conditions (including environmental factors) and production workflow;

- information about materials, employed computer aided design (CAD) software, employed machine, product design, post-processing conditions;

- process validation, i.e. process reproducibility;

- in case of personalized devices, information about patients' clinical parameters, imaging techniques and images' quality, and any changes applied to preexisted devices and manufacturing process must be documented [188].

The guidelines listed above have been provided to manufacturers as recommendations for device design, manufacturing and testing [189]; however, FDA is still working on more accurate regulations for AM processed and 3D-printed medical devices.

\section{Conclusion and future directions}

The employment of surgical meshes in clinical practice has revolutionized the way to approach some specific health conditions. Before the use of meshes, sutures were the main solution to manage hernia defects [190] and PFDs [35]. Passive dressings, such as gauzes, were mainly used to treat chronic wounds [48]. Implant muscles' coverage was the only choice in BR [38]. Periodontitis treatment mainly relied on the control of infection and disease progression [42]. Unfortunately, due to the high number of side effects and post-operative complications, the use of meshes in clinical practice is currently controversial and subjected to several limitations. Particularly, despite mesh implants employed in hernia repair are generally considered safe, they are still under careful observation [2], while those used in PFDs have been banned and/or are subjected to tight and strict regulations [177]. Membranes used in GBR are unable to properly mimic the complex structure of the 
periodontium, and more insights are required to assess the long-term stability of the regenerated bone tissue [42]. Additionally, further improvements are needed to design smart drug-eluting wound dressings [48] with a competitive cost [45]. Moreover, despite the interesting and promising field of application of meshes for BR, little is known about their use and with very limited research studies available.

As highlighted in the current review paper, most of the cited studies are at first experimental stages, proving that more tests must be carried out in order to prove in vivo feasibility of mesh implants. Moreover, human experimentation seems to be still far for some of these devices. However, the potential that mesh technology holds is high, especially considering the paucity of alternative treatments for these pathologies [5]. So, addressing the existing challenges is crucial.

Despite the progresses made in the design of antibacterial meshes, a better understanding of the complex tissue-device interactions is needed in order to propose new strategies aiming to modulate the immune reaction and infections and to achieve a better biomechanical compatibility [191]. To this end, exploiting the use of 3D bioprinting and MEW, in order to manufacture multi-material and/or multiarchitectural devices, is a promising approach to move forward and thus develop future implant with patient-specific and tailorable properties. Additionally, with the purpose to improve device bio-integration and tissue-mimicking ability, efforts should be placed in investigating combinations of antibacterial agents/biomolecules and cells. Even though the ideal mesh implant has not been developed yet, the promise of the latest research in the area can certainly be considered an interesting starting point for future developments in this field.

Acknowledgements The authors would like to thank Ulster University for the Ph.D. scholarship to Miss Francesca Corduas.

Author contributions Miss FC conducted the literature search and writing-original draft; Dr. DL contributed to writing-reviewing and editing, supervision, resources; Dr. EM contributed to writing-reviewing and editing, supervision, resources.

\section{Compliance with ethical standards}

Conflict of interest The authors declare that they have no conflict of interest.

Ethical approval This study does not contain any studies with human or animal subjects performed by any of the authors.

Open Access This article is licensed under a Creative Commons Attribution 4.0 International License, which permits use, sharing, adaptation, distribution and reproduction in any medium or format, as long as you give appropriate credit to the original author(s) and the source, provide a link to the Creative Commons licence, and indi- cate if changes were made. The images or other third party material in this article are included in the article's Creative Commons licence, unless indicated otherwise in a credit line to the material. If material is not included in the article's Creative Commons licence and your intended use is not permitted by statutory regulation or exceeds the permitted use, you will need to obtain permission directly from the copyright holder. To view a copy of this licence, visit http://creativecomm ons.org/licenses/by/4.0/.

\section{References}

1. Breast Implant Surgery, US Food and Drug Administration, US Food and Drug Administration (2019) https://www.fda. gov/medical-devices/breast-implants/breast-implant-surgery. Accessed 7 June 2020

2. Hernia Surgical Mesh Implants, US Food and Drug Administration, US Food and Drug Administration (2019) https://www.fda. gov/medical-devices/implants-and-prosthetics/hernia-surgicalmesh-implants. Accessed 7 June 2020

3. Baylón K, Rodríguez-Camarillo P, Elías-Zúñiga A, DíazElizondo J, Gilkerson R, Lozano K (2017) Past, present and future of surgical meshes: a review. Membranes 7:47. https://doi.org/1 $0.3390 /$ membranes 7030047

4. Hammoud M, Gerken J (2020) Inguinal hernia. In: StatPearls, StatPearls Publishing, Treasure Island (FL), pp 1-6. https://www. ncbi.nlm.nih.gov/books/NBK513332/. Accessed 7 June 2020

5. Mancuso E, Downey C, Doxford-Hook E, Bryant MG, Culmer P (2019) The use of polymeric meshes for pelvic organ prolapse: current concepts, challenges, and future perspectives. J Biomed Mater Res 108:771-789. https://doi.org/10.1002/jbm.b.34432

6. Rolph R, Farhadi J (2018) The use of meshes and matrices in breast reconstruction. Br J Hosp Med 79:454-459. https://doi.org/10.12 968/hmed.2018.79.8.454

7. Rodriguez IA, Selders GS, Fetz AE, Gehrmann CJ, Stein SH, Evensky JA, Green MS, Bowlin GL (2018) Barrier membranes for dental applications: a review and sweet advancement in membrane developments. Mouth Teeth 2. https://doi.org/10.15761/MTJ.100 0108

8. Gentile P, Chiono V, Tonda-Turo C, Ferreira AM, Ciardelli G (2011) Polymeric membranes for guided bone regeneration. Biotechnol J 6:1187-1197. https://doi.org/10.1002/biot.2011002 94

9. Vowden K, Vowden P (2017) Wound dressings: principles and practice. Surgery (Oxford) 35:489-494. https://doi.org/10.1016/ j.mpsur.2017.06.005

10. Logan Ellis H, Asaolu O, Nebo V, Kasem A (2016) Biological and synthetic mesh use in breast reconstructive surgery: a literature review. World J Surg Oncol 14:1-9. https://doi.org/10.1186/s129 57-016-0874-9

11. Gigliobianco G, Roman Regueros S, Osman NI, Bissoli J, Bullock AJ, Chapple CR, MacNeil S (2015) Biomaterials for pelvic floor reconstructive surgery: how can we do better? BioMed Res Int 2015:1-20. https://doi.org/10.1155/2015/968087

12. Barber S (2018) Briefing Paper: Surgical mesh implants. Available from https://commonslibrary.parliament.uk/researchbriefings/cbp-8108/

13. Urogynaecological Surgical Mesh Implants, Medsafe, Medsafe (n.d.). https://www.medsafe.govt.nz/hot/alerts/ UrogynaecologicaSurgicalMeshImplants.asp. Accessed 3 July 2020

14. Transvaginal (Urogynaecological) Surgical Mesh, Therapeutic Goods Administration, Therapeutic Goods Administration (TGA) (2019). https://www.tga.gov.au/hubs/transvaginal-mesh. Accessed 3 July 2020 
15. Guillaume O, Pérez-Tanoira R, Fortelny R, Redl H, Moriarty TF, Richards RG, Eglin D, Petter-Puchner A (2018) Infections associated with mesh repairs of abdominal wall hernias: are antimicrobial biomaterials the longed-for solution? Biomaterials 167:15-31. https://doi.org/10.1016/j.biomaterials.2018.03.017

16. Bottino MC, Thomas V, Schmidt G, Vohra YK, Chu T-MG, Kowolik MJ, Janowski GM (2012) Recent advances in the development of GTR/GBR membranes for periodontal regeneration - a materials perspective. Dent Mater 28:703-721. https://doi.org/10.101 6/j.dental.2012.04.022

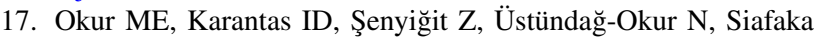
PI (2020) Recent trends on wound management: new therapeutic choices based on polymeric carriers. Asian J Pharm Sci. https:// doi.org/10.1016/j.ajps.2019.11.008

18. Kalaba S, Gerhard E, Winder JS, Pauli EM, Haluck RS, Yang J (2016) Design strategies and applications of biomaterials and devices for Hernia repair. Bioact Mater 1:2-17. https://doi.org/1 0.1016/j.bioactmat.2016.05.002

19. Farmer Z-L, Domínguez-Robles J, Mancinelli C, Larrañeta E, Lamprou DA (2020) Urogynecological surgical mesh implants: new trends in materials, manufacturing and therapeutic approaches. Int J Pharm 58:119512. https://doi.org/10.1016/j. ijpharm.2020.119512

20. Abrigo M, McArthur SL, Kingshott P (2014) Electrospun nanofibers as dressings for chronic wound care: advances, challenges, and future prospects. Macromol Biosci 14:772-792. https://doi.org/10.1002/mabi.201300561

21. Hernia Repair Devices and Consumables Market Growth—2027, Allied Market Research, Allied Market Research (n.d.). https:// www.alliedmarketresearch.com/hernia-repair-devices-market. Accessed 2 Oct 2020

22. Advanced Wound Care Market Size and Growth Analysis by 2027, Allied Market Research, Allied Market Research (n.d.). https://www.alliedmarketresearch.com/advanced-woundcare-market. Accessed 2 Oct 2020

23. Mikołajczyk Z, Walkowska A (2016) Design methodology of the strength properties of medical knitted meshes. IOP Conf Ser Mater Sci Eng 141:012012. https://doi.org/10.1088/1757-899X/141/1/0 12012

24. Wang See C, Kim T, Zhu D (2020) Hernia Mesh and Hernia repair: a review. Eng Regener 1:19-33. https://doi.org/10.1016/j.engreg. 2020.05.002

25. Bullen NL, Massey LH, Antoniou SA, Smart NJ, Fortelny RH (2019) Open versus laparoscopic mesh repair of primary unilateral uncomplicated inguinal hernia: a systematic review with metaanalysis and trial sequential analysis. Hernia 23:461-472. https:// doi.org/10.1007/s10029-019-01989-7

26. Krause L (2015) Ventral Hernia: risk factors, causes, and symptoms, healthline, healthline. https://www.healthline.com/health/ ventral-hernia. Accessed 6 July 2020

27. Amid PK, Shulman AG, Lichtenstein IL (1995) The Lichtenstein open "tension-free" mesh repair of inguinal Hernias. Surg Today 25:619-625. https://doi.org/10.1007/BF00311436

28. Pelvic Organ Prolapse (POP), US Food and Drug Administration, US Food and Drug Administration (2019) https://www.fda.gov/ medical-devices/urogynecologic-surgical-mesh-implants/pelvicorgan-prolapse-pop. Accessed 3 July 2020

29. Pizarro-Berdichevsky J, Clifton MM, Goldman HB (2015) Evaluation and management of pelvic organ prolapse in elderly women. Clin Geriatr Med 31:507-521. https://doi.org/10.1016/j.cger.201 5.06.008

30. Good MM, Solomon ER (2019) Pelvic floor disorders. Obstet Gynecol Clin North Am 46:527-540. https://doi.org/10.1016/j. ogc.2019.04.010

31. Stress Urinary Incontinence (SUI), US Food and Drug Administration, US Food and Drug Administration (2019) https:// www.fda.gov/medical-devices/urogynecologic-surgical-meshimplants/stress-urinary-incontinence-sui. Accessed 6 July 2020

32. Pelvic Organ Prolapse, National Health Service, National Health Service (2017). https://www.nhs.uk/conditions/pelvicorgan-prolapse/. Accessed 3 July 2020

33. Cervigni M, Natale F (2013) A comprehensive view on the actual trend in pelvic organ prolapse repair. Abdom Imaging 38:884-893. https://doi.org/10.1007/s00261-012-9960-9

34. Surgery and Procedures for Urinary Incontinence, National Health Service, National Health Service (2017). https://www.nhs.uk/ conditions/urinary-incontinence/surgery/. Accessed 3 July 2020

35. Mironska E, Chapple C, MacNeil S (2019) Recent advances in pelvic floor repair. F1000Res 8:1-11. https://doi.org/10.12688/f1 000research. 15046.1

36. Mastectomy, National Health Service, National Health Service (2017). https://www.nhs.uk/conditions/mastectomy/. Accessed 3 July 2020

37. Vidya R, Iqbal FM (2017) A guide to prepectoral breast reconstruction: a new dimension to implant-based breast reconstruction. Clin Breast Cancer 17:266-271. https://doi.org/10.1016/j.clbc.20 16.11.009

38. Kim S-E (2019) Prepectoral breast reconstruction. Yeungnam Univ J Med 36:201-207. https://doi.org/10.12701/yujm.2019.0 0283

39. Breast Reconstruction After Mastectomy, National Cancer Institute, National Cancer Institute (2016). https://www.cancer.gov/ types/breast/reconstruction-fact-sheet. Accessed 3 July 2020

40. Nanci A, Bosshardt DD (2006) Structure of periodontal tissues in health and disease*. Periodontol 2000(40):11-28. https://doi.org/ 10.1111/j.1600-0757.2005.00141.x

41. Sheikh Z, Hamdan N, Ikeda Y, Grynpas M, Ganss B, Glogauer M (2017) Natural graft tissues and synthetic biomaterials for periodontal and alveolar bone reconstructive applications: a review. Biomater Res 21:1-20. https://doi.org/10.1186/s40824-017-009 5-5

42. Liang Y, Luan X, Liu X (2020) Recent advances in periodontal regeneration: a biomaterial perspective. Bioact Mater 5:297-308. https://doi.org/10.1016/j.bioactmat.2020.02.012

43. Burns, World Health Organization, World Health Organization (n.d.). https://www.who.int/news-room/fact-sheets/detail/burns. Accessed 9 June 2020

44. Gohel M (2019) Chronic ulceration of the leg. Surgery (Oxford) 37:88-92. https://doi.org/10.1016/j.mpsur.2018.12.009

45. Kim HS, Sun X, Lee J-H, Kim H-W, Fu X, Leong KW (2019) Advanced drug delivery systems and artificial skin grafts for skin wound healing. Adv Drug Deliv Rev 146:209-239. https://doi. org/10.1016/j.addr.2018.12.014

46. Morton LM, Phillips TJ (2016) Wound healing and treating wounds. J Am Acad Dermatol 74:589-605. https://doi.org/10.1 016/j.jaad.2015.08.068

47. Frykberg RG, Banks J (2015) Challenges in the treatment of chronic wounds. Adv Wound Care 4:560-582. https://doi.org/1 0.1089/wound.2015.0635

48. Saghazadeh S, Rinoldi C, Schot M, Kashaf SS, Sharifi F, Jalilian E, Nuutila K, Giatsidis G, Mostafalu P, Derakhshandeh H, Yue K, Swieszkowski W, Memic A, Tamayol A, Khademhosseini A (2018) Drug delivery systems and materials for wound healing applications. Adv Drug Deliv Rev 127:138-166. https://doi.org/ 10.1016/j.addr.2018.04.008

49. Graça MFP, Miguel SP, Cabral CSD, Correia IJ (2020) Hyaluronic acid-based wound dressings: a review. Carbohydr Polym 241:1-17. https://doi.org/10.1016/j.carbpol.2020.116364

50. Cook LJ, Kovacs T (2018) Novel devices for implant-based breast reconstruction: is the use of meshes to support the lower pole justified in terms of benefits? A review of the evidence. Ecancer 12:1-16. https://doi.org/10.3332/ecancer.2018.796 
51. Todros S, Pavan PG, Natali AN (2016) Biomechanical properties of synthetic surgical meshes for pelvic prolapse repair. J Mech Behav Biomed Mater 55:271-285. https://doi.org/10.101 6/j.jmbbm.2015.10.024

52. Upsylon ${ }^{\mathrm{TM}}$ Y-Mesh \& Colpassist ${ }^{\mathrm{TM}}$ Vaginal Positioning Device, Boston Scientific-, Boston Scientific (n.d.). https:// www.bostonscientific.com/en-US/products/pelvic-floorreconstruction/upsylon-y-mesh.html. Accessed 7 July 2020

53. GORE-TEX ${ }^{\circledR}$ Soft Tissue Patch, Gore Medical, Gore Medical (n.d.). https://www.goremedical.com/products/stp. Accessed 7 July 2020

54. TiLOOP ${ }^{\circledR}$ Bra Pocket, Pfm Medical, Pfm Medical (n.d.). https:// www.pfmmedical.com/productcatalogue/mesh_implants_ breast_surgery/tiloopr_bra_pocket/index.html. Accessed 7 July 2020

55. TIGR ${ }^{\circledR}$ Matrix long-term resorbable mesh, Novus Scientific, Novus Scientific (n.d.). https://novusscientific.com/row/products/ tigr-matrix/. Accessed 7 July 2020

56. Mir M, Ali MN, Barakullah A, Gulzar A, Arshad M, Fatima S, Asad M (2018) Synthetic polymeric biomaterials for wound healing: a review. Prog Biomater 7:1-21. https://doi.org/10.1007/s40 204-018-0083-4

57. Dermagraft, Dermagraft, Dermagraft (n.d.). https://dermagraft. com/why-choose-dermagraft/. Accessed 8 July 2020

58. Alrubaiy L, Al-Rubaiy KK (2009) Skin substitutes: a brief review of types and clinical applications. Oman Med J 24:4-6. https:// doi.org/10.5001/omj.2009.2

59. Cytoflex ${ }^{\circledR}$ Tefguard $^{\circledR}$, Unicare Biomedical, Unicare Biomedical (n.d.). https://www.unicarebiomedical.com/dental-supplies/ cytoflex_ti_enforced.html. Accessed 15 June 2020

60. GUIDOR Matrix Barrier, Sunstar Group, Sunstar Group (n.d.). https://www.sunstar.com/healthy-thinking/guidor/. Accessed 7 July 2020

61. Geistlich Bio-Gide ${ }^{\circledR}$, Geistlich Pharma, Geistlich Pharma (n.d.). https://www.geistlich-pharma.com/en/dental/membranes/ geistlich-bio-gide/user-benefits/. Accessed 10 July 2020

62. Klinge U, Klosterhalfen B (2018) Mesh implants for hernia repair: an update. Expert Rev Med Dev 15:735-746. https://doi.org/10.1 080/17434440.2018.1529565

63. Bachour Y, Bargon CA, de Blok CJM, Ket JCF, Ritt MJPF, Niessen FB (2018) Risk factors for developing capsular contracture in women after breast implant surgery: a systematic review of the literature. J Plast Reconstruct Aesth Surg 71:29-48. https:// doi.org/10.1016/j.bjps.2018.05.022

64. Falagas ME, Velakoulis S, Iavazzo C, Athanasiou S (2007) Meshrelated infections after pelvic organ prolapse repair surgery. Eur J Obst Gynecol Reprod Biol 134:147-156. https://doi.org/10.101 6/j.ejogrb.2007.02.024

65. Wu Y-K, Cheng N-C, Cheng C-M (2019) Biofilms in chronic wounds: pathogenesis and diagnosis. Trends Biotechnol 37:505-517. https://doi.org/10.1016/j.tibtech.2018.10.011

66. Chadwick P, Ousey K (2019) Bacterial-binding dressings in the management of wound healing and infection prevention: a narrative review. J Wound Care 28:370-382

67. Mori-Cunha MGMC, Hympanova L, Rynkevic R, Mes T, Bosman AW, Deprest J (2019) Biomechanical behaviour and biocompatibility of ureidopyrimidinone-polycarbonate electrospun and polypropylene meshes in a hernia repair in rabbits. Materials 12:1174. https://doi.org/10.3390/ma12071174

68. Chen B, Dave B (2014) Challenges and future prospects for tissue engineering in female pelvic medicine and reconstructive surgery. Curr Urol Rep 15:425. https://doi.org/10.1007/s11934-014-04252

69. Rakhmatia YD, Ayukawa Y, Furuhashi A, Koyano K (2013) Current barrier membranes: titanium mesh and other membranes for guided bone regeneration in dental applications. J Prosth Res 57:3-14. https://doi.org/10.1016/j.jpor.2012.12.001

70. Zhu L-M (2015) Mesh implants: an overview of crucial mesh parameters. WJGS 7:226-237. https://doi.org/10.4240/wjgs.v7.i1 0.226

71. Watson B, Roberts J, Dobbs B, Roberts R (2020) Is inguinal hernia mesh safe? A prospective study. ANZ J Surg 90:538-541. https:// doi.org/10.1111/ans.15518

72. FDA Executive Summary, Surgical Mehs for Treatment of Women with Pelvic Organ Prolapse and Stress Urinary Incontinence (2011). https://www.tvt-messed-up-mesh.org.uk/pdfs/fdameeting-8-9th-sept-2011.pdf. Accessed 10 July 2020

73. Dieterich M, Paepke S, Zwiefel K, Dieterich H, Blohmer J, Faridi A, Klein E, Gerber B, Nestle-Kraemling C (2013) Implant-based breast reconstruction using a titanium-coated polypropylene mesh (TiLOOP Bra): a multicenter study of 231 cases. Plast Reconstr Surg 132:8e-19e. https://doi.org/10.1097/PRS.0b013e318290f8 $\mathrm{a} 0$

74. Evelhoch SR (2020) Biofilm and chronic nonhealing wound infections. Surg Clin North Am 100:727-732. https://doi.org/10.1016/ j.suc.2020.05.004

75. Lim G, Lin GH, Monje A, Chan HL, Wang HL (2018) Wound healing complications following guided bone regeneration for ridge augmentation: a systematic review and meta-analysis. Int J Oral Maxillofac Implants 33(1):41-50. https://doi.org/10.1160 7/jomi.5581

76. O'Brien FJ (2011) Biomaterials and scaffolds for tissue engineering. Mater Today 14:88-95. https://doi.org/10.1016/S1369-7021 (11)70058-X

77. Eichler C, Schulz C, Thangarajah F, Malter W, Warm M, Brunnert K (2019) A retrospective head-to-head comparison between TiLoop Bra/TiMesh ${ }^{\circledR}$ and Seragyn ${ }^{\circledR}$ in 320 cases of reconstructive breast surgery. Anticancer Res 39:2599-2605

78. Maddah HA (2016) Polypropylene as a promising plastic: a review. Am J Polym Sci 6:1-11. https://doi.org/10.5923/j.ajps. 20160601.01

79. Zhao Q, Liu Y, Müller-Steinhagen H, Liu G (2002) Graded Ni-P-PTFE coatings and their potential applications. Surf Coat Technol 155:279-284. https://doi.org/10.1016/S0257-8972(02)0 0116-0

80. Liu W, Tian X, Cui P, Li Y, Zheng K, Yang Y (2004) Preparation and characterization of PET/silica nanocomposites. J Appl Polym Sci 91:1229-1232. https://doi.org/10.1002/app.13284

81. Koizumi H, Takeuchi Y, Imai H, Kawai T, Yoneyama T (2019) Application of titanium and titanium alloys to fixed dental prostheses. J Prosth Res 63:266-270. https://doi.org/10.1016/j.jpor.2 019.04.011

82. Jem KJ, Tan B (2020) The development and challenges of poly(lactic acid) and poly(glycolic acid). Adv Ind Eng Polym Res 3:60-70. https://doi.org/10.1016/j.aiepr.2020.01.002

83. Roman S, Mangera A, Osman NI, Bullock AJ, Chapple CR, MacNeil S (2014) Developing a tissue engineered repair material for treatment of stress urinary incontinence and pelvic organ prolapse-which cell source? Which cell source? Neurourol Urodynam 33:531-537. https://doi.org/10.1002/nau.22443

84. Mir M, Ahmed N, ur Rehman A (2017) Recent applications of PLGA based nanostructures in drug delivery. Colloids Surf B Biointerf 159:217-231. https://doi.org/10.1016/j.colsurfb.2017.0 7.038

85. Choipang C, Chuysinuan P, Suwantong O, Ekabutr P, Supaphol P (2018) Hydrogel wound dressings loaded with PLGA/ciprofloxacin hydrochloride nanoparticles for use on pressure ulcers. J Drug Del Sci Technol 47:106-114. https://doi.org/ 10.1016/j.jddst.2018.06.025

86. de Melo LP, Salmoria GV, Fancello EA, de Roesler CRM (2017) Effect of injection molding melt temperatures on PLGA cranio- 
facial plate properties during in vitro degradation. Int $\mathrm{J}$ Biomater 2017:1-12. https://doi.org/10.1155/2017/1256537

87. Woodruff MA, Hutmacher DW (2010) The return of a forgotten polymer-polycaprolactone in the 21st century. Prog Polym Sci 35:1217-1256. https://doi.org/10.1016/j.progpolymsci.2010. 04.002

88. Shah SA, Sohail M, Khan S, Minhas MU, de Matas M, Sikstone V, Hussain Z, Abbasi M, Kousar M (2019) Biopolymer-based biomaterials for accelerated diabetic wound healing: a critical review. Int J Biol Macromol 139:975-993. https://doi.org/10.1 016/j.ijbiomac.2019.08.007

89. Leikina E, Mertts MV, Kuznetsova N, Leikin S (2002) Type I collagen is thermally unstable at body temperature. Proc Natl Acad Sci 99:1314-1318. https://doi.org/10.1073/pnas.032307099

90. Lee CH, Singla A, Lee Y (2001) Biomedical applications of collagen. Int J Pharm 221:1-22. https://doi.org/10.1016/S0378-517 3(01)00691-3

91. Szymańska E, Winnicka K (2015) Stability of chitosan-a challenge for pharmaceutical and biomedical applications. Mar Drugs 13:1819-1846. https://doi.org/10.3390/md13041819

92. Ren D, Yi H, Wang W, Ma X (2005) The enzymatic degradation and swelling properties of chitosan matrices with different degrees of N-acetylation. Carbohydr Res 340:2403-2410. https://doi.org/ 10.1016/j.carres.2005.07.022

93. Axibal E, Brown M (2019) Surgical dressings and novel skin substitutes. Dermatol Clin 37:349-366. https://doi.org/10.1016/j. det.2019.03.005

94. Jana S, Trivedi MK, Tallapragada RM, Branton A, Trivedi D, Nayak G, Mishra R (2015) Characterization of physicochemical and thermal properties of chitosan and sodium alginate after biofield treatment. Pharm Anal Acta 6:1-9. https://doi.org/10.41 72/2153-2435.1000430

95. Hao X, Silva E, Manssonbroberg A, Grinnemo K, Siddiqui A, Dellgren G, Wardell E, Brodin L, Mooney D, Sylven C (2007) Angiogenic effects of sequential release of VEGF-A165 and PDGF-BB with alginate hydrogels after myocardial infarction. Cardiovasc Res 75:178-185. https://doi.org/10.1016/j.cardiores. 2007.03.028

96. Wales E, Holloway S (2019) The use of prosthetic mesh for abdominal wall repairs: a semi-systematic-literature review. Int Wound J 16:30-40. https://doi.org/10.1111/iwj.12977

97. Domínguez-Robles J, Mancinelli C, Mancuso E, García-Romero I, Gilmore BF, Casettari L, Larrañeta E, Lamprou DA (2020) 3D Printing of drug-loaded thermoplastic polyurethane meshes: a potential material for soft tissue reinforcement in vaginal surgery. Pharmaceutics 12:1-15. https://doi.org/10.3390/pharmaceutics1 2010063

98. Haryńska A, Gubanska I, Kucinska-Lipka J, Janik H (2018) Fabrication and characterization of flexible medical-grade TPU filament for fused deposition modeling 3DP technology. Polymers 10:1-19. https://doi.org/10.3390/polym10121304

99. Bilsel Y, Abci I (2012) The search for ideal hernia repair; mesh materials and types. Int J Surg 10:317-321. https://doi.org/10.10 16/j.ijsu.2012.05.002

100. Kim JYS, Mlodinow AS (2017) What's new in acellular dermal matrix and soft-tissue support for prosthetic breast. Reconstr Plast Reconstruct Surg 140:30S-43S. https://doi.org/10.1097/PRS.000 0000000003950

101. Smith JR, Lamprou DA (2014) Polymer coatings for biomedical applications: a review. Trans IMF 92:9-19. https://doi.org/10.11 79/0020296713Z.000000000157

102. Ebersole GC, Buettmann EG, MacEwan MR, Tang ME, Frisella MM, Matthews BD, Deeken CR (2012) Development of novel electrospun absorbable polycaprolactone (PCL) scaffolds for hernia repair applications. Surg Endosc 26:2717-2728. https://doi. org/10.1007/s00464-012-2258-8
103. Xie H, Chen X, Shen X, He Y, Chen W, Luo Q, Ge W, Yuan W, Tang X, Hou D, Jiang D, Wang Q, Liu Y, Liu Q, Li K (2018) Preparation of chitosan-collagen-alginate composite dressing and its promoting effects on wound healing. Int J Biol Macromol 107:93-104. https://doi.org/10.1016/j.ijbiomac.2017.08.142

104. Shu-Tung L, Hui-Chen C, Natsuyo SL, Rushali R, Debbie Y (2013) A Comparative Study of Zimmer BioMend ${ }^{\circledR}$ And BioMend ${ }^{\circledR}$ Extend $^{\mathrm{TM}}$ Membranes Made at Two Different Manufacturing Facilities. https://www.zimmerbiometdental.com. Accessed 16 June 2020

105. Udpa N, Iyer SR, Rajoria R, Breyer KE, Valentine H, Singh B, McDonough SP, Brown BN, Bonassar LJ, Gao Y (2013) Effects of chitosan coatings on polypropylene mesh for implantation in a rat abdominal wall model. Tissue Eng Part A 19:2713-2723. https://doi.org/10.1089/ten.tea.2012.0739

106. Faulk DM, Londono R, Wolf MT, Ranallo CA, Carruthers CA, Wildemann JD, Dearth CL, Badylak SF (2014) ECM hydrogel coating mitigates the chronic inflammatory response to polypropylene mesh. Biomaterials 35:8585-8595. https://doi.org/ 10.1016/j.biomaterials.2014.06.057

107. Dwyer PL (2006) Evolution of biological and synthetic grafts in reconstructive pelvic surgery. Int Urogynecol J 17:10-15. https:// doi.org/10.1007/s00192-006-0103-0

108. Bissoli J, Bruschini H (2018) Scaffolds for pelvic floor prolapse: logical pathways. Int J Biomater 2018:1

109. Karlovsky ME, Thakre AA, Rastinehad A, Kushner L, Badlani GH (2005) Biomaterials for pelvic floor reconstruction. Urology 66:469-475. https://doi.org/10.1016/j.urology.2005.03.006

110. Jeon MJ, Bai SW (2007) Use of grafts in pelvic reconstructive surgery. Yonsei Med J 48:147-156

111. Kleiner LW, Wright JC, Wang Y (2014) Evolution of implantable and insertable drug delivery systems. J Control Release 181:1-10. https://doi.org/10.1016/j.jconrel.2014.02.006

112. Combating Antibiotic Resistance, US Food and Drug Administration, US Food and Drug Administration (2019). https://www. fda.gov/consumers/consumer-updates/combating-antibioticresistance. Accessed 9 June 2020

113. Rifampicin, US Food and Drug Administration, US Food and Drug Administration (n.d.). https://www.accessdata.fda.gov/ drugsatfda_docs/label/2010/050420s073,050627s012lbl.pdf. Accessed 9 June 2020

114. Reinbold J, Hierlemann T, Urich L, Uhde A-K, Müller I, Weindl T, Vogel U, Schlensak C, Wendel H-P, Krajewski S (2017) Biodegradable rifampicin-releasing coating of surgical meshes for the prevention of bacterial infections. DDDT 11:2753-2762. https://doi.org/10.2147/DDDT.S138510

115. Francisco EM (2018) Fluoroquinolone and quinolone antibiotics: PRAC recommends new restrictions on use following review of disabling potentially long-lasting side effects, European Medicines Agency, European Medicines Agency (2018). https://www.ema.europa.eu/en/news/fluoroquinolonequinolone-antibiotics-prac-recommends-new-restrictions-usefollowing-review. Accessed 9 June 2020

116. Guillaume O, Lavigne J-P, Lefranc O, Nottelet B, Coudane J, Garric X (2011) New antibiotic-eluting mesh used for soft tissue reinforcement. Acta Biomater 7:3390-3397. https://doi.org/10.1 016/j.actbio.2011.05.009

117. Florjanski W, Orzeszek S, Olchowy A, Grychowska N, Wieckiewicz W, Malysa A, Smardz J, Wieckiewicz M (2019) Modifications of polymeric membranes used in guided tissue and bone regeneration. Polymers 11:1-11. https://doi.org/10.3390/polym1 1050782

118. Ma S, Adayi A, Liu Z, Li M, Wu M, Xiao L, Sun Y, Cai Q, Yang X, Zhang X, Gao P (2016) Asymmetric collagen/chitosan membrane containing minocycline-loaded chitosan nanoparticles for guided 
bone regeneration. Sci Rep 6:1-10. https://doi.org/10.1038/srep3 1822

119. Dizaj SM, Lotfipour F, Barzegar-Jalali M, Zarrintan MH, Adibkia K (2014) Antimicrobial activity of the metals and metal oxide nanoparticles. Mater Sci Eng, C 44:278-284. https://doi.org/10.1 016/j.msec.2014.08.031

120. Muwaffak Z, Goyanes A, Clark V, Basit AW, Hilton ST, Gaisford S (2017) Patient-specific 3D scanned and 3D printed antimicrobial polycaprolactone wound dressings. Int J Pharm 527:161-170. https://doi.org/10.1016/j.ijpharm.2017.04.077

121. Chen P, Wu Z, Leung A, Chen X, Landao-Bassonga E, Gao J, Chen L, Zheng M, Yao F, Yang H, Lidgren L, Allan B, Liu Y, Wang T, Zheng M (2018) Fabrication of a silver nanoparticle-coated collagen membrane with anti-bacterial and anti-inflammatory activities for guided bone regeneration. Biomed Mater 13:1-14. https://doi. org/10.1088/1748-605X/aae15b

122. Marques L, Martinez G, Guidelli É, Tamashiro J, Segato R, Payão SLM, Baffa O, Kinoshita A (2020) Performance on bone regeneration of a silver nanoparticle delivery system based on natural rubber membrane NRL-AgNP. Coatings 10:1-15. https://doi.org/ 10.3390/coatings 10040323

123. Pérez-Köhler B, Fernández-Gutiérrez M, Pascual G, GarcíaMoreno F, San Román J, Bellón JM (2016) In vitro assessment of an antibacterial quaternary ammonium-based polymer loaded with chlorhexidine for the coating of polypropylene prosthetic meshes. Hernia 20:869-878. https://doi.org/10.1007/s10029-01 6-1537-z

124. Inoue BS, Streit S, dos Santos Schneider AL, Meier MM (2020) Bioactive bacterial cellulose membrane with prolonged release of chlorhexidine for dental medical application. Int J Biol Macromol 148:1098-1108. https://doi.org/10.1016/j.ijbiomac.2020.01.036

125. FDA Drug Safety Communication: FDA warns about rare but serious allergic reactions with the skin antiseptic chlorhexidine gluconate, US Food and Drug Administration, US Food and Drug Administration (2019). https://www.fda.gov/drugs/drug-safetyand-availability/fda-drug-safety-communication-fda-warnsabout-rare-serious-allergic-reactions-skin-antiseptic. Accessed 10 June 2020

126. Wang T, Zhu X-K, Xue X-T, Wu D-Y (2012) Hydrogel sheets of chitosan, honey and gelatin as burn wound dressings. Carbohydr Polym 88:75-83. https://doi.org/10.1016/j.carbpol.2011.11.069

127. Mancuso E, Tonda-Turo C, Ceresa C, Pensabene V, Connell SD, Fracchia L, Gentile P (2019) Potential of Manuka Honey as a natural polyelectrolyte to develop biomimetic nanostructured meshes with antimicrobial properties. Front Bioeng Biotechnol 7:1-13. https://doi.org/10.3389/fbioe.2019.00344

128. Jung RE, Glauser R, Schärer P, Hämmerle CHF, Sailer HF, Weber FE (2003) Effect of rhBMP-2 on guided bone regeneration in humans: a randomized, controlled clinical and histomorphometric study. Clin Oral Implant Res 14:556-568. https://doi.org/10.103 4/j.1600-0501.2003.00921.x

129. Ansarizadeh M, Mashayekhan S, Saadatmand M (2019) Fabrication, modeling and optimization of lyophilized advanced platelet rich fibrin in combination with collagen-chitosan as a guided bone regeneration membrane. Int J Biol Macromol 125:383-391. https://doi.org/10.1016/j.ijbiomac.2018.12.078

130. Wang Y, Cao Z, Cheng R, Qin M, Zhang D, Deng L, Chen X, Cui W (2019) Immunomodulated electrospun fibrous scaffolds via bFGF camouflage for pelvic regeneration. Appl Mater Today 15:570-581. https://doi.org/10.1016/j.apmt.2019.04.005

131. Brown C, Finch J (2010) Which mesh for hernia repair? Annals 92:272-278. https://doi.org/10.1308/003588410X126641920762 96

132. Murugan R, Ramakrishna S (2007) Design strategies of tissue engineering scaffolds with controlled fiber orientation. Tissue Eng 13:1845-1866. https://doi.org/10.1089/ten.2006.0078
133. Chen S, Li R, Li X, Xie J (2018) Electrospinning: an enabling nanotechnology platform for drug delivery and regenerative medicine. Adv Drug Deliv Rev 132:188-213. https://doi.org/1 0.1016/j.addr.2018.05.001

134. Mohammed A, Elshaer A, Sareh P, Elsayed M, Hassanin H (2020) Additive manufacturing technologies for drug delivery applications. Int J Pharm 580:1-24. https://doi.org/10.1016/j.ijpharm.20 20.119245

135. Zelkó R, Lamprou DA, Sebe I (2020) Recent development of electrospinning for drug delivery. Pharmaceutics 12:1-5. https:// doi.org/10.3390/pharmaceutics 12010005

136. Liu M, Zhang Y, Sun S, Khan AR, Ji J, Yang M, Zhai G (2019) Recent advances in electrospun for drug delivery purpose. J Drug Target 27:270-282. https://doi.org/10.1080/1061186X.2018.148 1413

137. Lian H, Meng Z (2017) Melt electrospinning vs. solution electrospinning: a comparative study of drug-loaded poly $(\varepsilon-$ caprolactone) fibres. Mater Sci Eng 74:117-123. https://doi.org/ 10.1016/j.msec.2017.02.024

138. Sill TJ, von Recum HA (2008) Electrospinning: applications in drug delivery and tissue engineering. Biomaterials 29:1989-2006. https://doi.org/10.1016/j.biomaterials.2008.01.011

139. Hall-Barrientos IJ, Paladino E, Szabó P, Brozio S, Hall PJ, Oseghale CI, Passarelli MK, Moug SJ, Black RA, Wilson CG, Zelkó R, Lamprou DA (2017) Electrospun collagen-based nanofibres: a sustainable material for improved antibiotic utilisation in tissue engineering applications. Int J Pharm. 531:67-79. https:// doi.org/10.1016/j.ijpharm.2017.08.071

140. Nikmaram N, Roohinejad S, Hashemi S, Koubaa M, Barba FJ, Abbaspourrad A, Greiner R (2017) Emulsion-based systems for fabrication of electrospun nanofibers: food, pharmaceutical and biomedical applications. RSC Adv 7:28951-28964. https://doi. org/10.1039/C7RA00179G

141. Hall Barrientos IJ, Paladino E, Brozio S, Passarelli MK, Moug S, Black RA, Wilson CG, Lamprou DA (2017) Fabrication and characterisation of drug-loaded electrospun polymeric nanofibers for controlled release in hernia repair. Int J Pharm 517:329-337. https://doi.org/10.1016/j.ijpharm.2016.12.022

142. Hall-Barrientos I, MacKenzie G, Wilson C, Lamprou D, Coats P (2019) Biological performance of electrospun polymer fibres. Materials 12:363. https://doi.org/10.3390/ma12030363

143. 5 Things to Know About Triclosan, US Food and Drug Administration, US Food and Drug Administration (2019). https://www. fda.gov/consumers/consumer-updates/5-things-know-abouttriclosan. Accessed 16 June 2020

144. Khalf A, Madihally SV (2017) Recent advances in multiaxial electrospinning for drug delivery. Eur J Pharm Biopharm 112:1-17. https://doi.org/10.1016/j.ejpb.2016.11.010

145. He P, Zhong Q, Ge Y, Guo Z, Tian J, Zhou Y, Ding S, Li H, Zhou C (2018) Dual drug loaded coaxial electrospun PLGA/PVP fiber for guided tissue regeneration under control of infection. Mater Sci Eng C 90:549-556. https://doi.org/10.1016/j.msec.2018.04.0 14

146. Prado-Prone G, Silva-Bermudez P, Almaguer-Flores A, GarcíaMacedo JA, García VI, Rodil SE, Ibarra C, Velasquillo C (2018) Enhanced antibacterial nanocomposite mats by coaxial electrospinning of polycaprolactone fibers loaded with Zn-based nanoparticles. Nanomed Nanotechnol Biol Med 14:1695-1706. https://doi.org/10.1016/j.nano.2018.04.005

147. Hansen SG, Taskin MB, Chen M, Wogensen L, Vinge-Nygaard J, Axelsen SM (2019) Electrospun nanofiber mesh with fibroblast growth factor and stem cells for pelvic floor repair. J Biomed Mater Res. https://doi.org/10.1002/jbm.b.34364

148. Zhang C, Feng F, Zhang H (2018) Emulsion electrospinning: fundamentals, food applications and prospects. Trends Food Sci Technol 80:175-186. https://doi.org/10.1016/j.tifs.2018.08.005 
149. Pant B, Park M, Park S-J (2019) Drug delivery applications of core-sheath nanofibers prepared by coaxial electrospinning: a review. Pharmaceutics 11:1-21. https://doi.org/10.3390/ pharmaceutics 11070305

150. Jain R, Shetty S, Yadav KS (2020) Unfolding the electrospinning potential of biopolymers for preparation of nanofibers. J Drug Del Sci Technol 57:1-15. https://doi.org/10.1016/j.jddst.2020.10160 4

151. Mangır N, Bullock AJ, Roman S, Osman N, Chapple C, MacNeil S (2016) Production of ascorbic acid releasing biomaterials for pelvic floor repair. Acta Biomater 29:188-197. https://doi.org/1 0.1016/j.actbio.2015.10.019

152. Doostmohammadi M, Forootanfar H, Ramakrishna S (2020) Regenerative medicine and drug delivery: progress via electrospun biomaterials. Mater Sci Eng C 109:1-21. https://doi.org/10. 1016/j.msec.2019.110521

153. Szymczyk-Ziółkowska P, Łabowska MB, Detyna J, Michalak I, Gruber P (2020) A review of fabrication polymer scaffolds for biomedical applications using additive manufacturing techniques. Biocybern Biomed Eng 40:624-638. https://doi.org/10.1 016/j.bbe.2020.01.015

154. Giannitelli SM, Mozetic P, Trombetta M, Rainer A (2015) Combined additive manufacturing approaches in tissue engineering. Acta Biomater 24:1-11. https://doi.org/10.1016/j.actbio.2015.06. 032

155. Miramini S, Fegan KL, Green NC, Espino DM, Zhang L, ThomasSeale LEJ (2020) The status and challenges of replicating the mechanical properties of connective tissues using additive manufacturing. J Mech Behav Biomed Mater 103:1-22. https://doi. org/10.1016/j.jmbbm.2019.103544

156. Brunello G, Sivolella S, Meneghello R, Ferroni L, Gardin C, Piattelli A, Zavan B, Bressan E (2016) Powder-based 3D printing for bone tissue engineering. Biotechnol Adv 34:740-753. https://doi. org/10.1016/j.biotechadv.2016.03.009

157. Hassan M, Dave K, Chandrawati R, Dehghani F, Gomes VG (2019) 3D printing of biopolymer nanocomposites for tissue engineering: nanomaterials, processing and structure-function relation. Eur Polymer J 121:1-15. https://doi.org/10.1016/j. eurpolymj.2019.109340

158. Moroni L, Boland T, Burdick JA, De Maria C, Derby B, Forgacs G, Groll J, Li Q, Malda J, Mironov VA, Mota C, Nakamura M, Shu W, Takeuchi S, Woodfield TBF, Xu T, Yoo JJ, Vozzi G (2018) Biofabrication: a guide to technology and terminology. Trends Biotechnol 36:384-402. https://doi.org/10.1016/j.tibtech.2017.1 0.015

159. Gu Z, Fu J, Lin H, He Y (2019) Development of 3D bioprinting: from printing methods to biomedical applications. Asian J Pharm Sci 1:29. https://doi.org/10.1016/j.ajps.2019.11.003

160. Stanković M, Frijlink HW, Hinrichs WLJ (2015) Polymeric formulations for drug release prepared by hot melt extrusion: application and characterization. Drug Discov Today 20:812-823. https://doi.org/10.1016/j.drudis.2015.01.012

161. Mathew E, Domínguez-Robles J, Stewart SA, Mancuso E, O’Donnell K, Larrañeta E, Lamprou DA (2019) Fused deposition modeling as an effective tool for anti-infective dialysis catheter fabrication. ACS Biomater Sci Eng 5:6300-6310. https://doi.org/ 10.1021/acsbiomaterials.9b01185

162. Mobaraki M, Ghaffari M, Yazdanpanah A, Luo Y, Mills DK (2020) Bioinks and bioprinting: a focused review. Bioprinting 18:1-16. https://doi.org/10.1016/j.bprint.2020.e00080

163. Qamar N, Abbas N, Irfan M, Hussain A, Arshad MS, Latif S, Mehmood F, Ghori MU (2019) Personalized 3D printed ciprofloxacin impregnated meshes for the management of hernia. J Drug Del Sci Technol 53:1-8. https://doi.org/10.1016/j.jddst.2 019.101164
164. Baek W, Kim MS, Park DB, Joo OY, Lee WJ, Roh TS, Sung H-J (2019) Three-dimensionally printed breast reconstruction devices facilitate nanostructure surface-guided healthy lipogenesis. ACS Biomater Sci Eng 5:4962-4969. https://doi.org/10.102 1/acsbiomaterials.9b00985

165. Shim J-H, Won J-Y, Sung S-J, Lim D-H, Yun W-S, Jeon Y-C, Huh J-B (2015) Comparative efficacies of a 3D-printed PCL/PLGA/ $\beta$ TCP membrane and a titanium membrane for guided bone regeneration in beagle dogs. Polymers 7:2061-2077. https://doi. org/10.3390/polym7101500

166. Wang S, Xiong Y, Chen J, Ghanem A, Wang Y, Yang J, Sun B (2019) Three dimensional printing bilayer membrane scaffold promotes wound healing. Front Bioeng Biotechnol 7:1-11. https://doi.org/10.3389/fbioe.2019.00348

167. Afghah F, Ullah M, Seyyed Monfared Zanjani J, Akkuş Süt P, Sen O, Emanet M, Saner-Okan B, Culha M, Menceloglu Y, Yildiz M, Koc B (2020) 3D printing of silver-doped polycaprolactone-poly propylene succinate composite scaffolds for skin tissue engineering. Biomed Mater 15:035015. https://doi.org/10.1088/1748-605 $\mathrm{X} / \mathrm{ab} 7417$

168. Dalton PD (2017) Melt electrowriting with additive manufacturing principles. Curr Opin Biomed Eng 2:49-57. https://doi.org/1 0.1016/j.cobme.2017.05.007

169. Robinson TM, Hutmacher DW, Dalton PD (2019) The next frontier in melt electrospinning: taming the jet. Adv Funct Mater 29:1904664. https://doi.org/10.1002/adfm.201904664

170. Hewitt E, Mros S, Mcconnell M, Cabral J, Ali A (2019) Meltelectrowriting with novel milk protein/PCL biomaterials for skin regeneration. Biomed Mater 1:16. https://doi.org/10.1088/1748605X/ab3344

171. Dubey N, Ferreira JA, Daghrery A, Aytac Z, Malda J, Bhaduri SB, Bottino MC (2020) Highly tunable bioactive fiberreinforced hydrogel for guided bone regeneration. Acta Biomater 113:164-176. https://doi.org/10.1016/j.actbio.2020.06.011

172. Paul K, Darzi S, Mcphee G, Borgo MD, Werkmeister JA, Gargett CE, Mukherjee S (2019) 3D bioprinted endometrial stem cells on melt electrospun PCL meshes for pelvic floor application promote anti-inflammatory responses in mice. Social Science Research Network, Rochester. https://papers.ssrn.com/abstract=3 387674. Accessed 8 Nov 2019

173. Habiboallah G, Mahdi Z, Majid Z, Nasroallah S, Taghavi AM, Forouzanfar A, Arjmand N (2014) Enhancement of gingival wound healing by local application of silver nanoparticles periodontal dressing following surgery: a histological assessment in animal model. MRI 03:128-138. https://doi.org/10.4236/mri.201 4.33016

174. García-Salinas S, Evangelopoulos M, Gámez-Herrera E, Arruebo M, Irusta S, Taraballi F, Mendoza G, Tasciotti E (2020) Electrospun anti-inflammatory patch loaded with essential oils for wound healing. Int J Pharm 577:119067. https://doi.org/10.101 6/j.ijpharm.2020.119067

175. Urogynecologic Surgical Mesh Implants, US Food and Drug Administration, US Food and Drug Administration (2019). https://www.fda.gov/medical-devices/implants-and-prosthetics/ urogynecologic-surgical-mesh-implants. Accessed 19 June 2020

176. FDA's Activities: Urogynecologic Surgical Mesh, US Food and Drug Administration, US Food and Drug Administration. (2019). https://www.fda.gov/medical-devices/urogynecologic-surgicalmesh-implants/fdas-activities-urogynecologic-surgical-mesh. Accessed 9 July 2020

177. Barber S (2019) Briefing Paper: Surgical mesh implants. Available from https://commonslibrary.parliament.uk/researchbriefings/cbp-8108/

178. Vaginal Mesh Surgery Should be a Last Resort, National Health Service, National Health Service (2018). https://www.nhs.uk/ 
news/medical-practice/vaginal-mesh-surgery-should-be-lastresort-says-nice/. Accessed 19 June 2020

179. Medical Devices: Guidance for Manufacturers on Vigilance, GOV.UK, GOV.UK. (n.d.). https://www.gov.uk/government/ collections/medical-devices-guidance-for-manufacturers-onvigilance. Accessed 19 June 2020

180. Considerations about Surgical Mesh for SUI, US Food and Drug Administration, US Food and Drug Administration. (2019). https://www.fda.gov/medical-devices/urogynecologicsurgical-mesh-implants/considerations-about-surgical-mesh-sui. Accessed 9 July 2020

181. Lockhart K, Dunn D, Teo S, Ng JY, Dhillon M, Teo E, van Driel ML (2018) Comparing surgical groin hernia repair performed with or without mesh. Cochrane Datab Syst Rev. https://doi.org/10.10 02/14651858.CD011517.pub2

182. Hernia Surgical Mesh Implants: Reporting Problems to the FDA, US Food and Drug Administration, US Food and Drug Administration (2018). https://www.fda.gov/medical-devices/ hernia-surgical-mesh-implants/hernia-surgical-mesh-implantsreporting-problems-fda. Accessed 9 July 2020

183. Antimicrobial Dressings, National Institute for Health and Care, National Institute for Health and Care (n.d.). https://bnf.nice.org. uk/wound-management/antimicrobial-dressings.html. Accessed 11 July 2020

184. Honey Dressings, National Institute for Health and Care, National Institute for Health and Care (n.d.). https://bnf.nice.org. uk/wound-management/honey-dressings.html. Accessed 11 July 2020

185. Brouillard C, Bursztejn A-C, Latarche C, Cuny J-F, Truchetet F, Goullé J-P, Schmutz J-L (2018) Silver absorption and toxicity evaluation of silver wound dressings in 40 patients with chronic wounds. J Eur Acad Dermatol Venereol 32:2295-2299. https:// doi.org/10.1111/jdv. 15055
186. Silver Dressings, National Institute for Health and Care, National Institute for Health and Care (n.d.). https://bnf.nice.org. uk/wound-management/silver-dressings.html. Accessed 11 July 2020

187. Statement by FDA Commissioner Scott Gottlieb, M.D., on FDA ushering in new era of 3D printing of medical products; provides guidance to manufacturers of medical devices, US Food and Drug Administration, US Food and Drug Administration (2020). https://www.fda.gov/news-events/press-announcements/ statement-fda-commissioner-scott-gottlieb-md-fda-usheringnew-era-3d-printing-medical-products. Accessed 10 July 2020

188. Technical Considerations for Additive Manufactured Medical Devices-Guidance for Industry and Food and Drug Administration Staff, US Food and Drug Administration (2017)

189. FDA's Role in 3D Printing, US Food and Drug Administration, US Food and Drug Administration (2019). https://www.fda. gov/medical-devices/3d-printing-medical-devices/fdas-role-3dprinting. Accessed 10 July 2020

190. Sathasivam R, Bussa G, Viswanath Y, Obuobi R-B, Gill T, Reddy A, Shanmugam V, Gilliam A, Thambi P (2019) 'Mesh hiatal hernioplasty' versus 'suture cruroplasty' in laparoscopic para-oesophageal hernia surgery; a systematic review and metaanalysis. Asian J Surg 42:53-60. https://doi.org/10.1016/j.asjsur. 2018.05.001

191. Mangir N, Roman S, Chapple CR, MacNeil S (2020) Complications related to use of mesh implants in surgical treatment of stress urinary incontinence and pelvic organ prolapse: infection or inflammation? World J Urol 38:73-80. https://doi.org/10.100 7/s00345-019-02679-w 